\title{
Study on the wheel/rail adhesion restoration and damage evolution in the single application of alumina particles
}

SHI, L. B.; LI, Q.; KVARDA, D.; GALAS, R.; OMASTA, M.; WANG, W. J.; GUO, J.; LIU, Q. Y.

Wear

2019, vol. 426-427, Part B, April 2019, pp. 1807-1819

ISSN: 0043-1648

DOI: https://doi.org/10.1016/j.wear.2019.01.021

Accepted manuscript

(C) 2019. This manuscript version is made available under the CC-BY-NC-ND 4.0 license (http://creativecommons.org/licenses/by-nc-nd/4.0/), doi: 10.1016/j.wear.2019.01.021

Final version available from

https://www.sciencedirect.com/science/article/pii/S0043164819300328 


\title{
Study on the wheel/rail adhesion restoration and damage evolution in the single application of alumina particles
}

\author{
L.B. Shi ${ }^{1}$, Q. Li ${ }^{1}$, D. Kvarda ${ }^{2}$, R. Galas ${ }^{2}$, M. Omasta ${ }^{2}$, W.J. Wang ${ }^{1 *}$, J. Guo ${ }^{1}$, Q.Y. Liu ${ }^{1}$ \\ 1.Tribology Research Institute, State Key Laboratory of Traction Power, Southwest Jiaotong University, \\ Chengdu 610031, China 2. Faculty of Mechanical Engineering, Brno University of Technology, Czech
}

$$
\text { Republic }
$$

\begin{abstract}
The aim of this study is to explore the wheel/rail adhesion restoration performance of alumina particles and the comparison between the continuous and single application test strategies in twin disc simulation. The results indicate that the single application test strategy performs better on evaluating the adhesion restoring ability of solid particles. In the single application tests, the restored adhesion coefficient increases with the applied alumina quantity and final gets stable when the quantity exceeds $2 \mathrm{~g}(0.607 \mathrm{~g} / \mathrm{m})$. However, the increase of alumina quality could always extend the duration of restored adhesion. The alumina particles at the size in the range of 0.075 to $0.15 \mathrm{~mm}$ showed the best adhesion restoration and the longest duration was achieved at the size of $0.15 \mathrm{~mm}$. In addition, it is observed that the serious damage is mainly caused in the particles crushing process, and will be gradually ground off in the following long running to have no threat on the serving life of the wheel and the rail.
\end{abstract}

Keywords: Adhesion restoration; Alumina; Quantity; Particle size; Wear damage

\section{Introduction}

Sanding is a common adhesion restoration strategy widely used in the railway to overcome the poor adhesion problems. Low adhesion coefficient generally takes place when water [1-4], oil [4, 5], leaf [4, 6-8], the third-body layer [9-11] or other contamination $[12,13]$ 
presents in the wheel/rail interface preventing the contact between metal micro asperities in the wheel/rail interface. Sand particles create new contact asperities in the wheel/rail interface to provide the mechanical shearing force in the relative motion of the wheel and the rail surfaces $[14,15]$. Besides sand, other solid particles with higher hardness than the wheel/rail steels can also help to improve the adhesion coefficient under low adhesion conditions [16, 17]. Among them, alumina particles have been proved to have better adhesion restoration performance than sand and have been used practically in Japan [18].

Although some parameters of sanding have been stated in some railway standards [19, 20], most of them are loose rules and some of them are not the same in different countries [21]. There have been many studies in the lab or field to evaluate the adhesion restoring performance of solid particles. The particle size and feeding rate were generally studied to estimate their effects on the adhesion restoring ability $[4,15,17,21-28]$, wear and damage deterioration [15, 17, 21, 22, 24-26] and contact conductance [29]. In the previous studies, except for Arias-Cuevas's [22] field and Lewis's [23] linear full-scale studies, most of them were conducted on some large- or small-scale twin disc rigs. They adopted the continuous or single application test strategy to simulate the practical sanding process. In the continuous application simulation tests, sand or other solid particles are applied into the rolling contact interface continuously at a small-scale sand flow rate (generally no more than $50 \mathrm{~g} / \mathrm{min}$ ) [15, $17,18,24,25]$ taking no sand deposition rate into consideration or a larger one to meet a desired deposition rate (generally use the practical rate of $7.5 \mathrm{~g} / \mathrm{m}$ ) on the discs surface $[4,21$, $26,29]$. In the single application tests, the dose of applied particles is also designed from the expected deposition rates $[27,28]$. However, the continuous application strategy uses the 
discs rolling distance per minute or second to design the required flow rate, while the single application just takes the disc circumference as reference.

Considering the different motion and scale between the wheel/rail and simulation discs, the strategy adopted in the experiments to entrain the solid particles into the contact interface seems to be crucial for the measured results. This is why different conclusions might be drawn in different researches. However, there was not a systematic study to compare which type of experiments is better. Arias-Cuevas had ever adopted both of these two strategies in his twin disc sanding studies under leaf condition $[21,28]$. In his continuous application study, the measured influence of particle size on the adhesion recovery was opposite to the field [22] and single application tests results [28], which seemed to be caused by the too rapid remove of leaf layer by the continuous entrainment of sand particles. To better clarify such an uncertain effect caused by the different test strategies, there should be some more comparative studies to take other simulated sanding parameters, surface conditions and damage into consideration.

This work uses the alumina particles as adhesion enhancer in the adhesion restoration tests. At first, both continuous and single application tests will be conducted for comparison. Then, the effect of particle size and quantity of alumina particles on the adhesion restoration ability and duration will be explored. In the end, a new perspective on the surface damage evolution will be drawn using the single application test strategy.

\section{Experimental details}

\subsection{Experimental apparatus}


A JD-1 wheel/rail simulation facility was used to carry out the adhesion tests, shown in Fig.1. This facility has been frequently used in previous studies to reveal the wheel/rail adhesion characteristics under various conditions $[3,30]$. There is a small disc with a diameter of $210 \mathrm{~mm}$ serving as the wheel roller and a large disc with a diameter of $1050 \mathrm{~mm}$ serving as the rail roller. The contact between the wheel and rail rollers is loaded hydraulically to achieve a preset normal load and the speed difference of the wheel/rail rollers is controlled to achieve the desired creep ratio. The adhesion coefficient is described as the ratio of the tangential friction force and normal force in the contact.

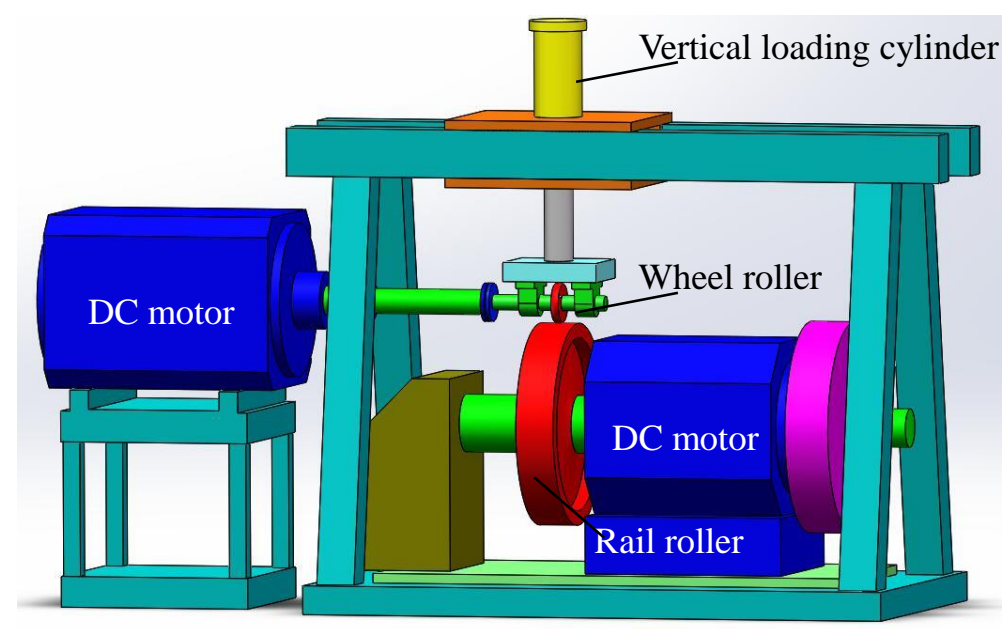

(a)

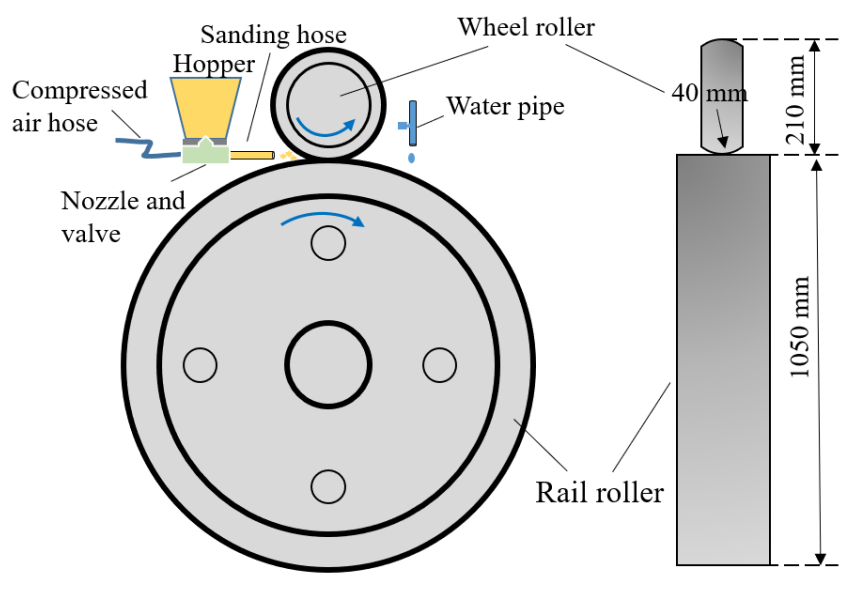

(b)

Fig.1. Scheme of JD-1 wheel/rail simulation facility and rollers, (a) JD-1 wheel/rail simulation facility; (b) 
wheel/rail rollers.

Tests for wear and damage evolution were conducted on an MJP rolling-sliding apparatus, which uses two $55 \mathrm{~mm}$ discs cut from the wheel tread and rail head serving as the wheel and rail rollers, respectively. Schematic structures of this machine and rollers are shown in Fig.3. The wheel/rail rollers are driven by two individual motors and the normal force of the rollers is loaded by a hydraulic system. The creep ratio could be realized by adjusting the rotational speed of the wheel roller to reach a precise difference. More details about this facility could be found in [31].

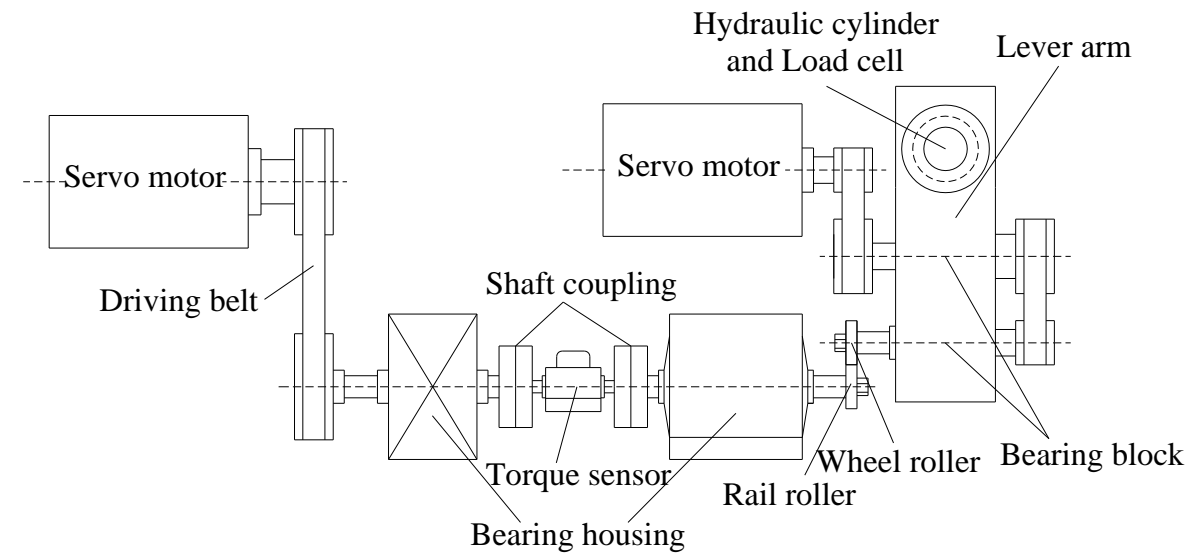

(a)

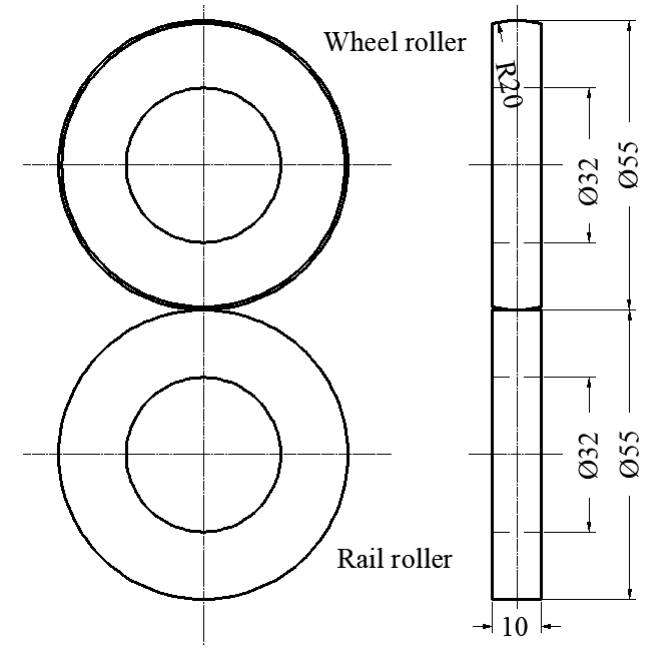

(b)

Fig.2. Scheme of MJP rolling-sliding wear and contact fatigue apparatus and rollers, (a) MJP rolling-sliding 
wear and contact fatigue apparatus; (b) wheel/rail rollers.

For the application of adhesion enhancers, a developed sanding system similar to the real sander box was used to blow the particles into the contact interface in the rolling direction, as shown in Fig.1b. By adjusting the compressed air and the valve of the nozzle, different flow rates could be achieved in the continuous application. For the single application of different quantity, a certain amount of alumina particles was put into the sanding hose in advance and then blown out of the hose during a fixed period of approximately 1 second.

\subsection{Experimental parameters and procedure}

In this study, the creep ratio in both adhesion and wear tests was set as 5\%, at which the macro sliding or spinning of wheels would be determined in the field and sanding would be triggered automatically to prevent these problems. The creep ratio in the tests is defined as the following formula.

$$
\text { creep ratio }=\frac{\omega_{\text {rail }} r_{\text {rail }}-\omega_{\text {wheel }} r_{\text {wheel }}}{\omega_{\text {rail }} r_{\text {rail }}}
$$

Where, $\omega_{\text {rail }}$ and $\omega$ wheel are the rotational speed of rail and wheel rollers; $r_{\text {rail }}$ and $r$ wheel are the radius of the wheel and rail rollers, respectively. To achieve the desired creep ratio, the rolling speed of the rail roller was set as $120 \mathrm{rpm}$ and the wheel roller speed was controlled to $570 \mathrm{rpm}$ on JD-1 wheel/rail simulation facility. While the speed of wheel and rail rollers on MJP rolling-sliding apparatus was set as 190 and $200 \mathrm{rpm}$. The normal load applied in adhesion and wear tests were 1760 and $410 \mathrm{~N}$, respectively, simulating the maximum wheel/rail contact pressure of 1100 and $1500 \mathrm{MPa}$.

In the tests, water kept dropping on the rail surface to simulate low adhesion condition and the alumina particles with $\mathrm{Al}_{2} \mathrm{O}_{3}$ content more than $96 \%$ were used as the adhesion 
enhancers. The alumina particles had been well sieved into different sizes before the tests. The wheel and rail rollers on JD-1 wheel/rail simulation facility are made of the wheel and rail steel applied in the field. Their chemical compositions could be seen from [30]. The rollers used on MJP rolling-sliding wear and contact fatigue apparatus were directly cut from the tread of a CL60 wheel and the head of an U71Mn rail, which are similar with the material of JD-1 rollers. The chemical compositions and hardness of the wheel/rail rollers are given in Table 1.

Table 1. Chemical compositions and hardness of wheel/rail rollers (wt \%).

\begin{tabular}{ccccccc}
\hline Roller & $\mathrm{C}$ & $\mathrm{Si}$ & $\mathrm{Mn}$ & $\mathrm{P}$ & $\mathrm{S}$ & Hardness $/ \mathrm{HV}_{0.2}$ \\
\hline Wheel & $0.55 \sim 0.65$ & $0.17 \sim 0.37$ & $0.58 \sim 0.80$ & $\leq 0.04$ & $\leq 0.045$ & 310 \\
Rail & $0.62 \sim 0.77$ & $0.15 \sim 0.37$ & $1.35 \sim 1.65$ & $\leq 0.04$ & $\leq 0.050$ & 287 \\
\hline
\end{tabular}

First, the alumina particles with different flow rates (ranging from 1.5 to $500 \mathrm{~g} / \mathrm{min}$ ) were applied continuously into the wheel/rail interface under wet condition, in order to study the effect of flow rate on the improved adhesion characteristics, as listed in Table 2. Then, tests were conducted by single application of alumina particles to explore the effect of particle size (ranging from 0.02 to $0.8 \mathrm{~mm}$ ) and applied quantity (ranging from 0.03 to $25 \mathrm{~g}$ ) on the improved adhesion coefficient and the duration of restored adhesion. More details about the tests have been listed in Table 3. These tests were repeated twice in the study to ensure the results are reliable and repeatable. The single application tests of $2 \mathrm{~g}$ alumina particles at the size of $0.3 \mathrm{~mm}$ were also conducted on the MJP to trace the evolution of wear damage in the process of before-when-after applying the alumina particles. Four pairs of wheel/rail rollers started from the running-in process with fresh surfaces but would be stopped at different stages, as shown in Fig.3. Furthermore, the morphologies of the worn surface and subsurface 
of the rollers were observed using optical microscopy (OM) (OLYMPUS, Japan) and scanning electron microscope (SEM), (JSM-7001F, Japan).

Table 2. Details for the adhesion tests with continuous application of sand/alumina particles.

\begin{tabular}{ccccc}
\hline Condition & Particles & Size $/ \mathrm{mm}$ & Flow rate/g/min & Duration \\
\hline \multirow{2}{*}{ Wet $/ 5 \mathrm{ml} / \mathrm{min}$} & Alumina & & $1.5,12,30,60$, & \\
& Sand & 0.3 & $125,200,500$ & 2 240 Cycles \\
& & & 1.5 & \\
\hline
\end{tabular}

Table 3. Details for the adhesion tests with single application of alumina particles.

\begin{tabular}{cccc}
\hline Condition & Particle size $/ \mathrm{mm}$ & Quantity $/ \mathrm{g}$ & Duration \\
\hline Wet $/ 5 \mathrm{ml} / \mathrm{min}$ & 0.3 & $0.03,0.2,0.5,1,2$, & \\
& $\begin{array}{c}0.02,0.038,0.075, \\
0.1,0.15,0.3,\end{array}$ & 2 & $\begin{array}{c}\text { Last until the } \\
\text { improved adhesion } \\
\text { coefficient drops to } \\
\text { the low level again }\end{array}$ \\
Wet $/ 1 \mathrm{ml} / \mathrm{min}$ & $0.4,0.8$ & & \\
Wet $/ 5 \mathrm{ml} / \mathrm{min}$ & 0.3 & 2 & \\
Oil/1 $/ \mathrm{ml} / \mathrm{min}$ & & & \\
\hline
\end{tabular}

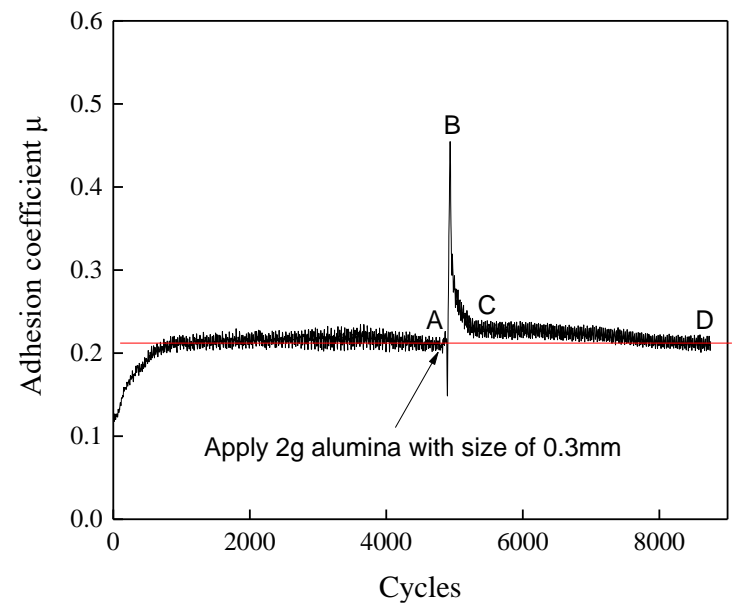

Fig.3. Wear tests stopped at different stages (A, B, C and D) in the process of before-when-after applying the alumina particles.

\section{Results}

\subsection{Adhesion coefficient in the continuous application of alumina particles}


Water is the most common contamination in the railway to drop the adhesion coefficient below the requirement of the normal operation of locomotives. The adhesion curves in Fig.4 indicate that the adhesion coefficient under dry and wet conditions is approximately 0.6 and 0.25 , respectively. Sanding is an effective strategy restoring the adhesion coefficient to approximately 0.34 . Alumina particles seem to be more effective than sanding, which could restore the adhesion coefficient to approximately 0.41 .

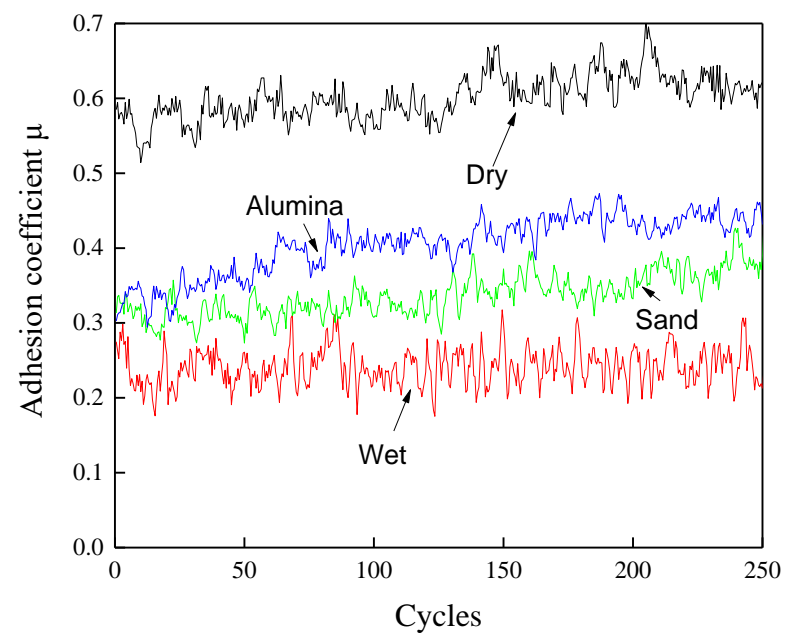

Fig.4. Comparison of the adhesion restoration with the continuous application of sand and alumina particles under wet conditions (particle size: $0.3 \mathrm{~mm}$, flow rate: $1.5 \mathrm{~g} / \mathrm{min}$ ).

When the flow rate of alumina particles increases from 1.5 to $30 \mathrm{~g} / \mathrm{min}$, the adhesion coefficient is sharply improved from 0.41 to the maximum value of 0.56 , as shown in Fig.5. However, with the continuous increase of flow rate, the adhesion coefficient could not be further improved but reduced to lower values. Especially, when the flow rate is increased to a large value of $500 \mathrm{~g} / \mathrm{min}$, the adhesion restoring ability of the alumina particles almost diminishes. In addition, it could also be observed in Fig.5a that the adhesion curves at the flow rates of 1.5 and $12 \mathrm{~g} / \mathrm{min}$ keep rising from the beginning of the application of alumina particles until to the end of the tests, while the rise ends in the middle of the test at the flow 
rate of $30 \mathrm{~g} / \mathrm{min}$. When the flow rate exceeds $60 \mathrm{~g} / \mathrm{min}$, the adhesion coefficient curves approach the maximum values as soon as the application begins and then turn to descend. At the flow rate of $500 \mathrm{~g} / \mathrm{min}$, the adhesion coefficient is always low from the beginning of the application.

To clearly illustrate the comparing of the restored adhesion at different flow rate, the average adhesion coefficient per 20 cycles has been used in Fig.5a to replace the raw adhesion curves. But it is still worthy noted there are big fluctuations of adhesion coefficient curves and strong vibration observed in the tests at the flow rates of 125, 200 and $500 \mathrm{~g} / \mathrm{min}$, as shown in Fig.5b. The strong vibration at the test of $500 \mathrm{~g} / \mathrm{min}$ could even separate the wheel/rail contact in some moments, terminating the further tests at higher sanding rates.

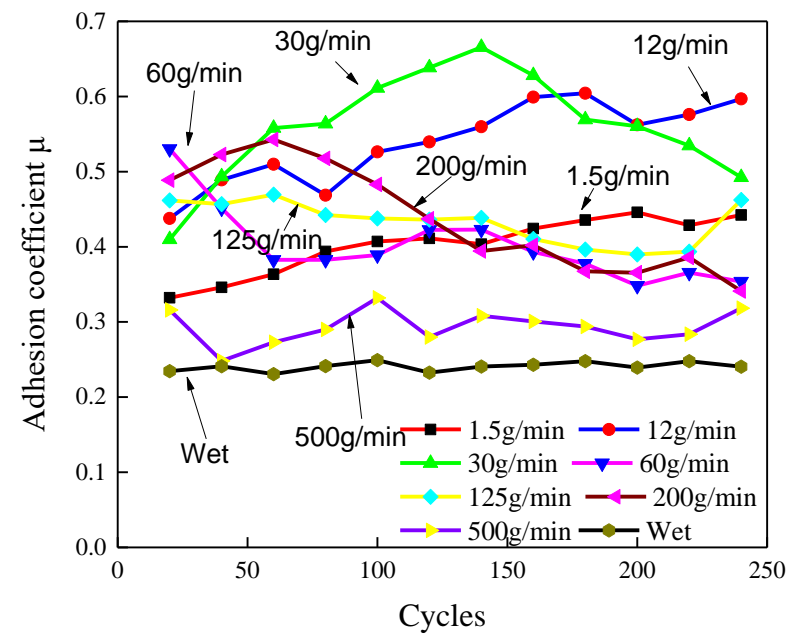

(a)

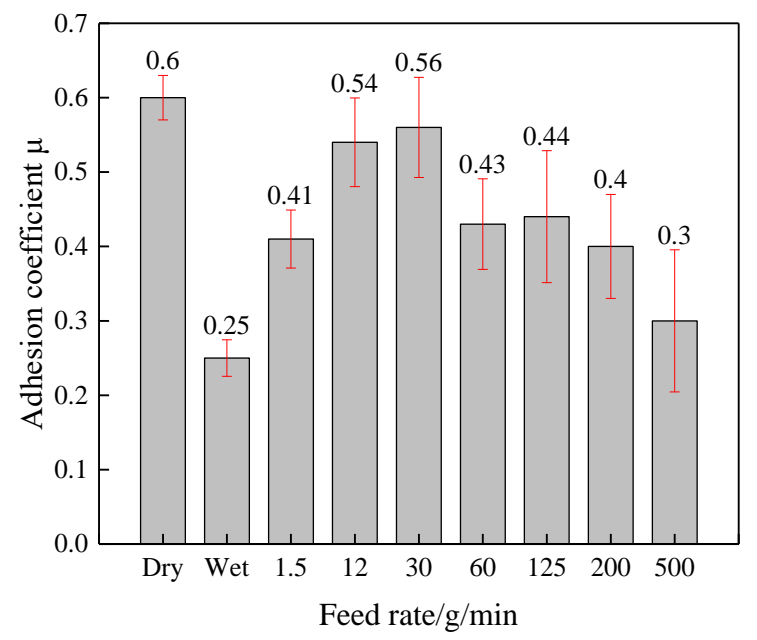

(b)

Fig.5. Effect of continuous application flow rate of alumina particles on the improved adhesion coefficient (particle size of $0.3 \mathrm{~mm}$ ), (a) adhesion coefficient curves; (b) average adhesion coefficient.

\subsection{Adhesion coefficient in the single application of alumina particles}

It could be observed from Fig. 6 that there is always an immediate increase of adhesion coefficient from $\mu_{0}$ to $\mu_{1}$ after the single application of alumina particles and then the adhesion 
coefficient drops to $\mu_{2}$ after a short duration $t_{1}$. The peak adhesion coefficient $\mu_{1}$ in the immediate increase of adhesion coefficient could corresponds to the applied quantity directly. While the following adhesion coefficient $\mu_{2}$ (defined as the average adhesion coefficient from $300-400$ cycles after the peak point) is still higher than the initial adhesion coefficient $\mu_{0}$ (wet condition), which may be because of there are still some crushed particles remaining on the surface after most of the applied particles have be wiped off in the duration $t_{1}$.

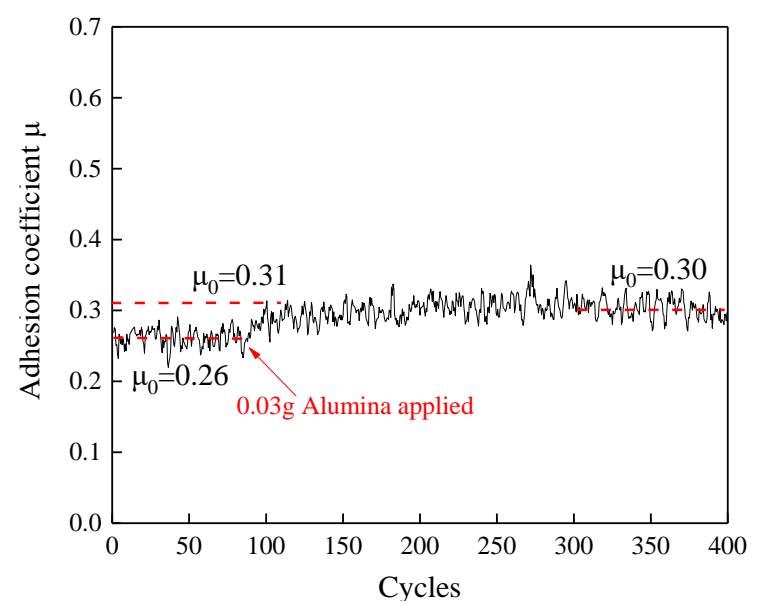

(a)

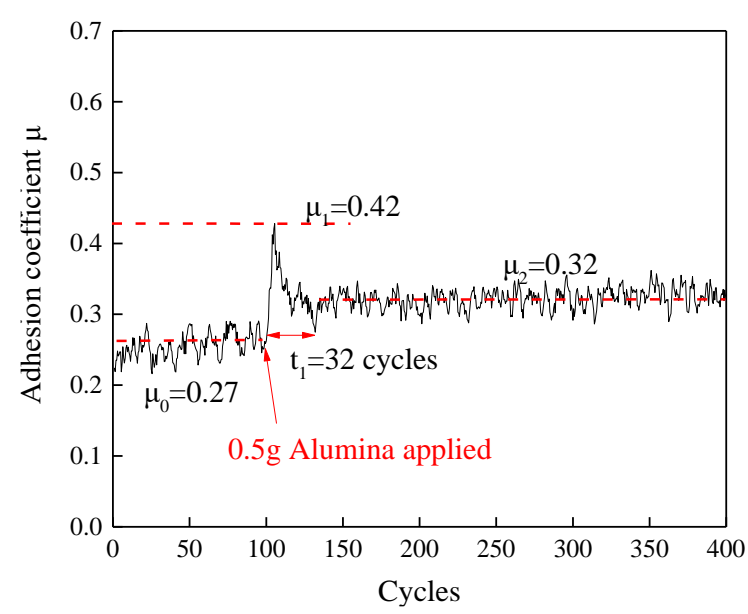

(c)

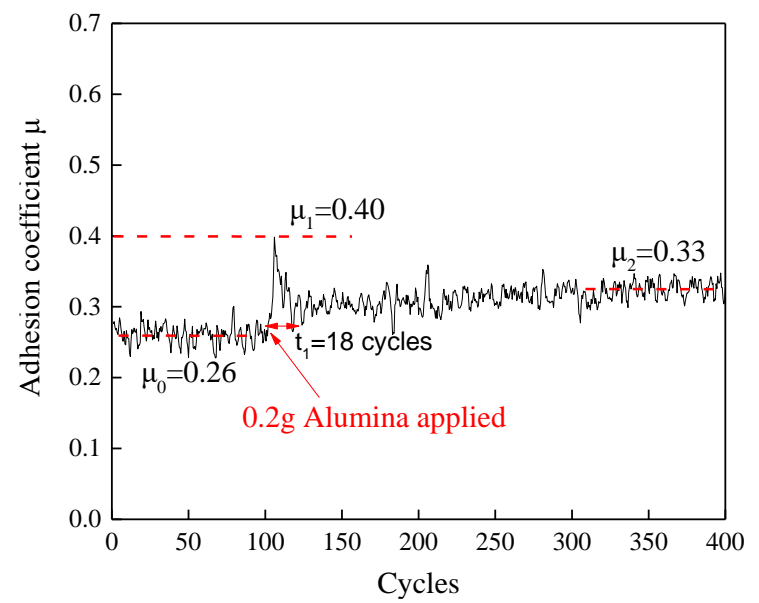

(b)

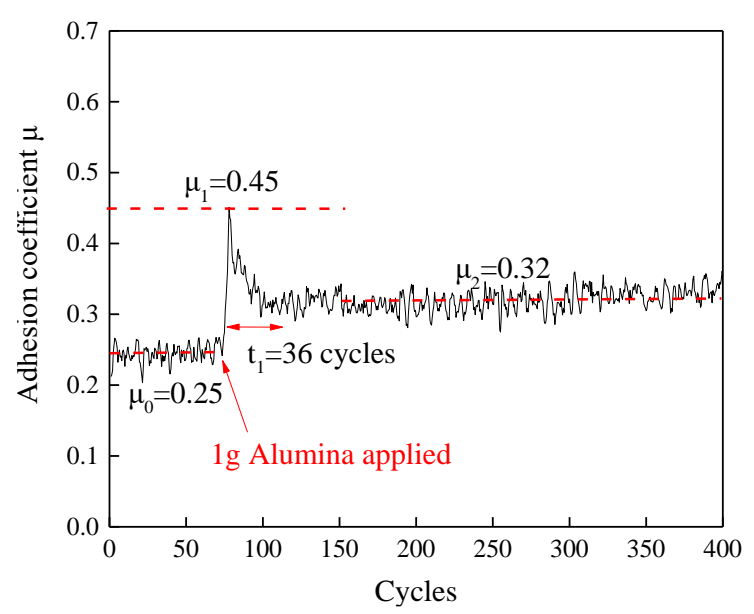

(d) 


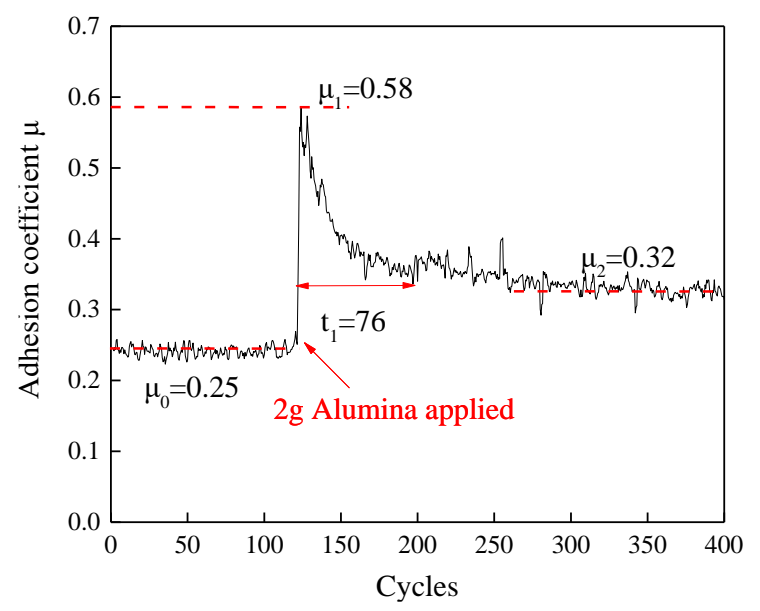

(e)

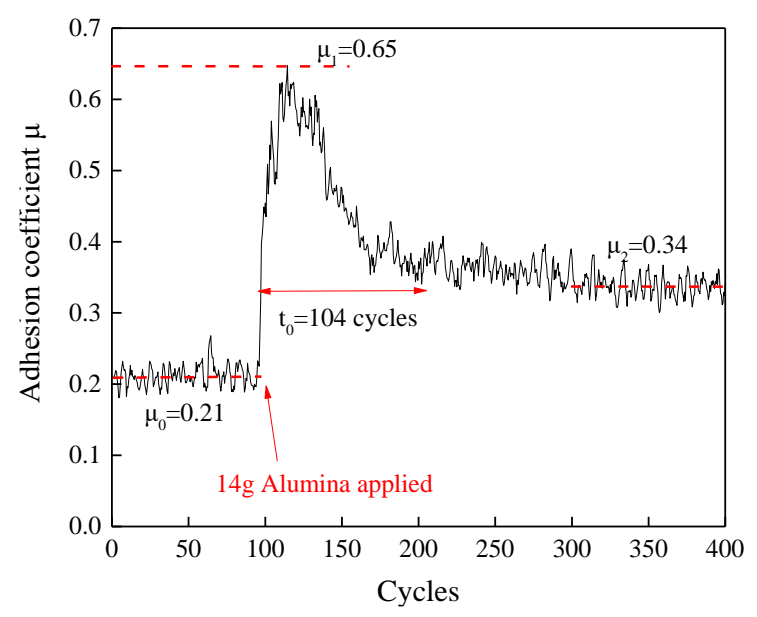

(g)

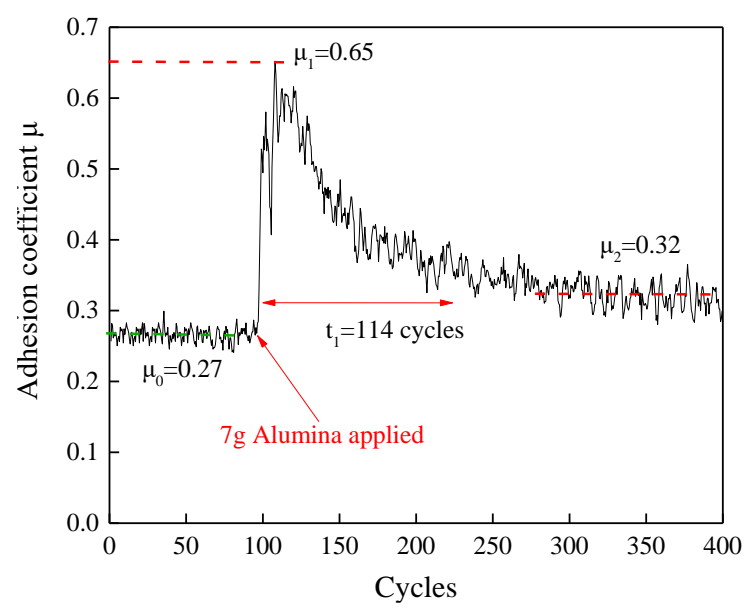

(f)

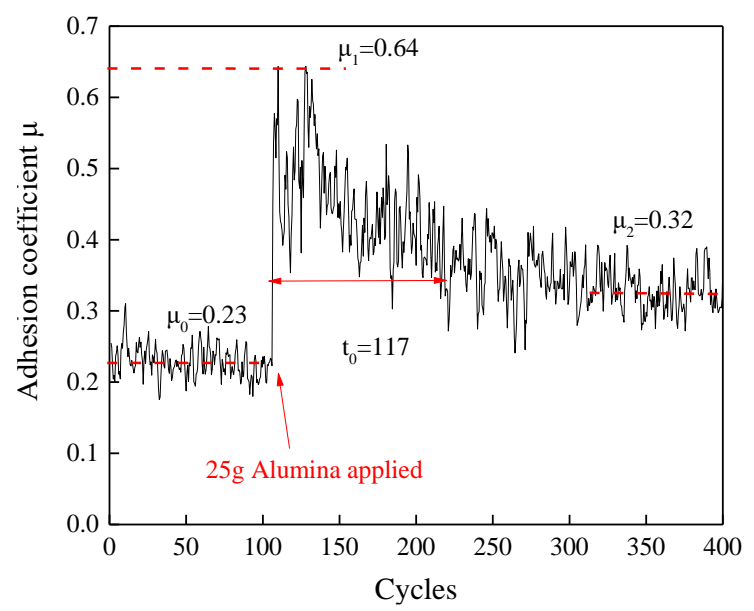

(h)

Fig.6. The adhesion restoration after the single application of different quantities of alumina particles

(particle size of $0.3 \mathrm{~mm}$ ).

The adhesion restoration is not significant when $0.03 \mathrm{~g}$ alumina particles is applied (Fig.6a). The adhesion restoration could be strengthened with the increase of applied quantity until reaching a threshold quantity of 2 g (Fig.6a-f). As summarized in Fig.7, the restored adhesion coefficient $\mu_{1}$ sharply increases with the quantity increasing from 0.03 to $2 \mathrm{~g}$, and then turns to be stable with the further increase of quantity from 7 to $25 \mathrm{~g}$. The followed adhesion coefficient $\mu_{2}$ always keeps stable in different cases (Fig.7), which indicates the 
residual particles on the surface at this stage don't have significant effects on the adhesion coefficient.

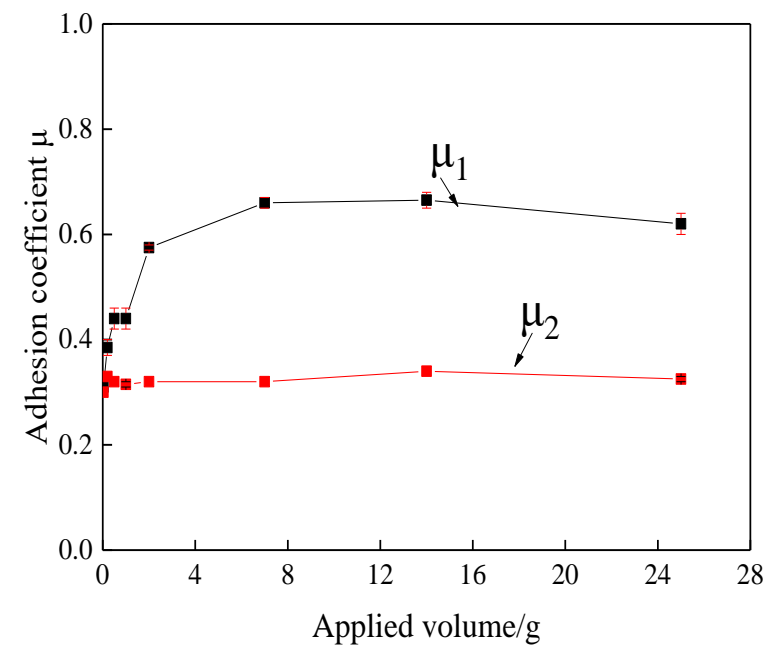

Fig.7. Effect of the applied quantity of alumina particles on $\mu_{1}$ and $\mu_{2}$.

Choosing $2 \mathrm{~g}$ as the base quantity, the results achieved by single application of alumina particles at different sizes are presented in Fig.8. Similar with the results presented in Fig.6, the grain size also highly effects the restored adhesion coefficient $\mu_{1}$, but has less effect on the final adhesion coefficient $\mu_{2}$. The variation of $\mu_{1}$ with the increasing particle size in Fig.9 shows the best adhesion restoration is achieved by the alumina particles at the sizes of 0.075 to $0.15 \mathrm{~mm}$. Above $0.15 \mathrm{~mm}$, the alumina particles could still meet the adhesion restoration needs, but the peak adhesion coefficient begins to decrease with the increasing particle size.

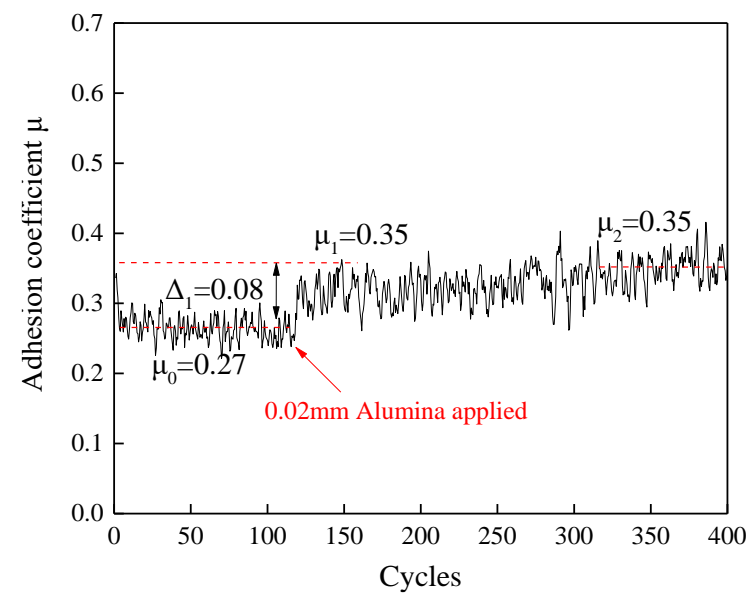

(a)

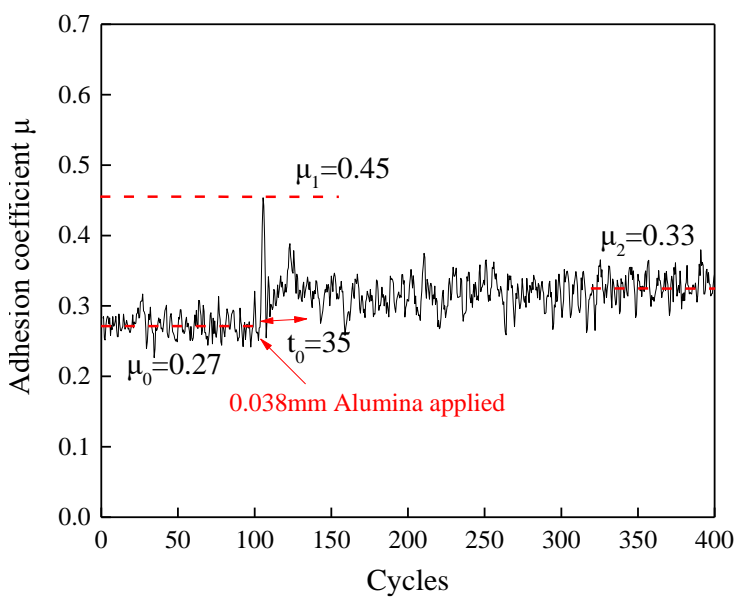

(b) 


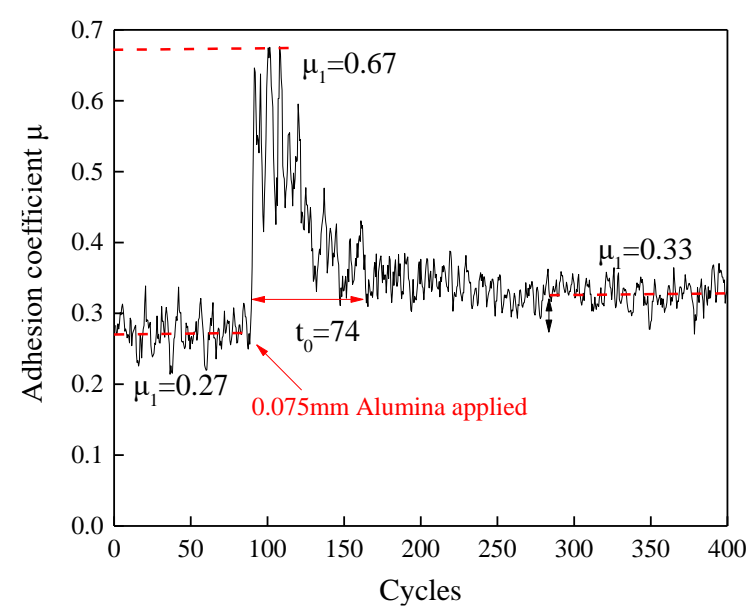

(c)

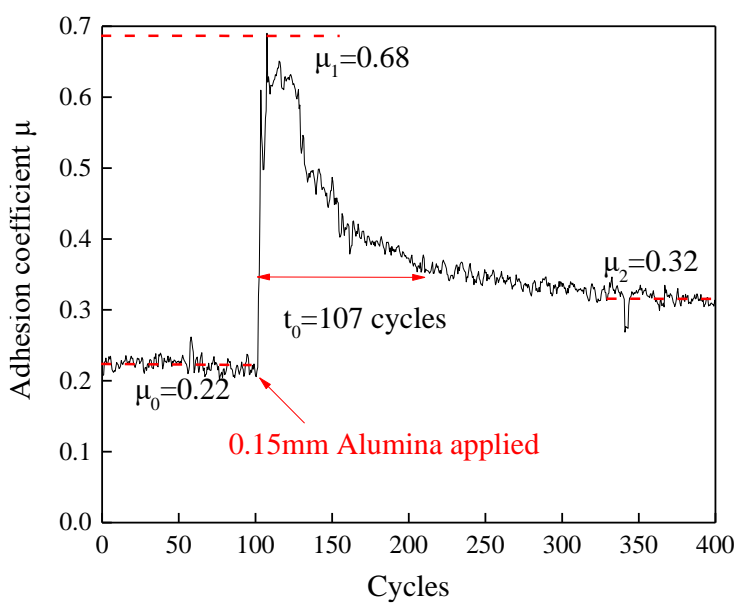

(e)

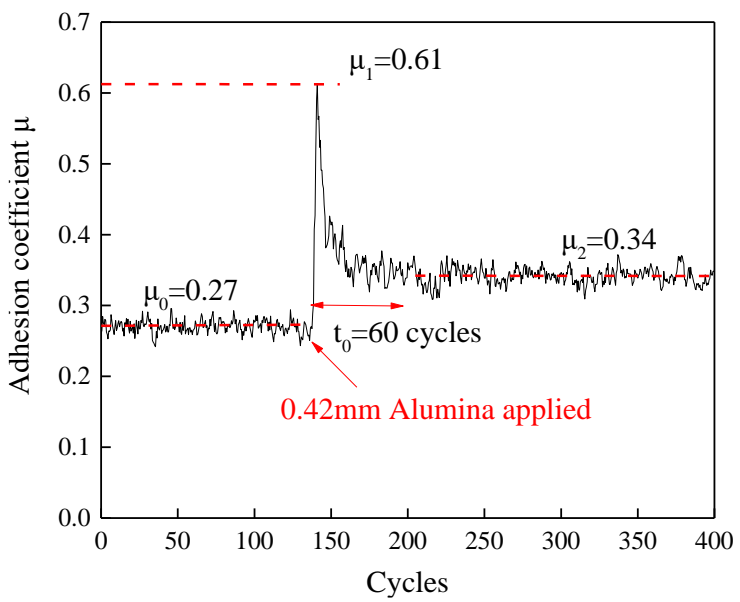

(g)

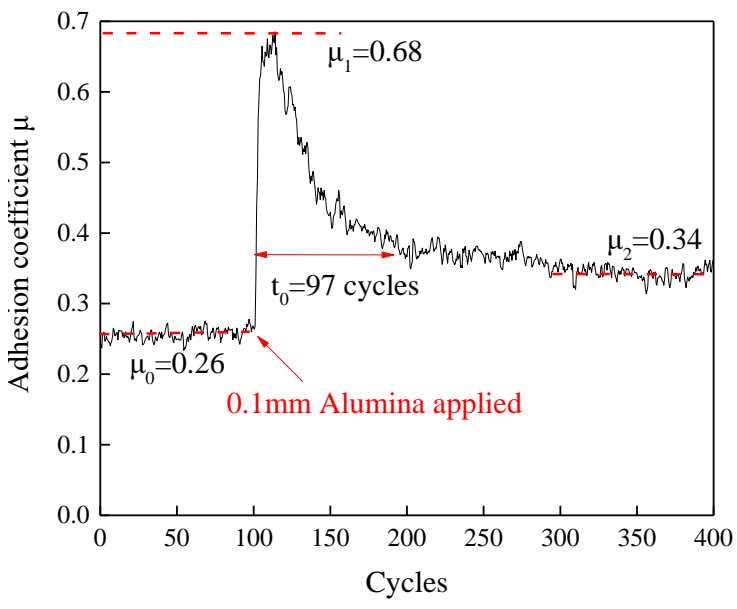

(d)

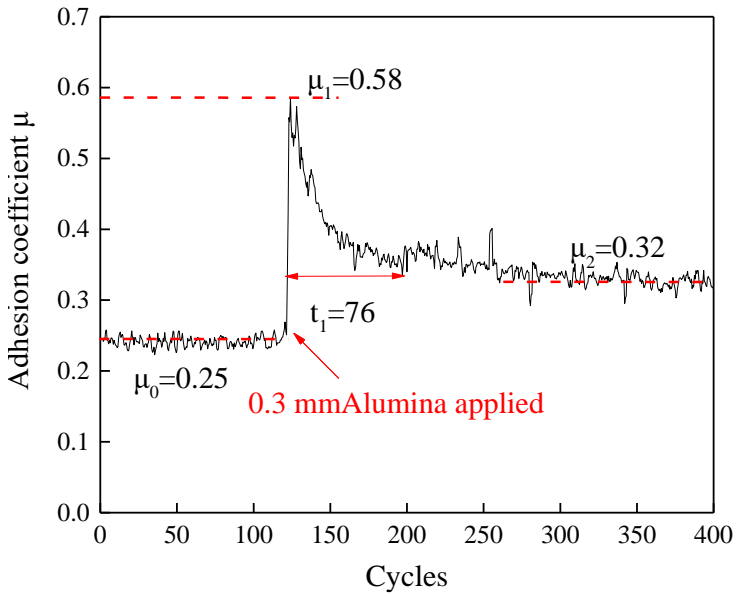

(f)

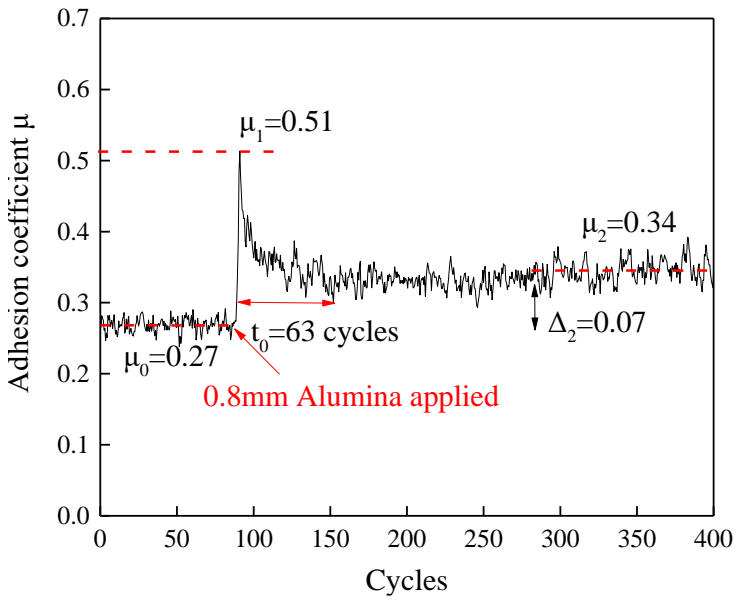

(h)

Fig.8. The adhesion restoration after the single application of alumina particles at different sizes (applied 
quantity of $2 \mathrm{~g}$ ).

It is worth noting that when the applied alumina particles are infinitesimal (0.03 g, Fig.6a) or micro (0.02 mm, Fig.8a), the peak adhesion coefficient $\mu_{1}$ is almost same with the following stable adhesion coefficient $\mu_{2}$. The decreasing process from $\mu_{1}$ to $\mu_{2}$ could not be distinguished, although the actual quantity and particle size of the particles at these two stages are certainly different. That indicates the adhesion restoring ability of the particles won't be remarkable when either of the size or quantity is too small.

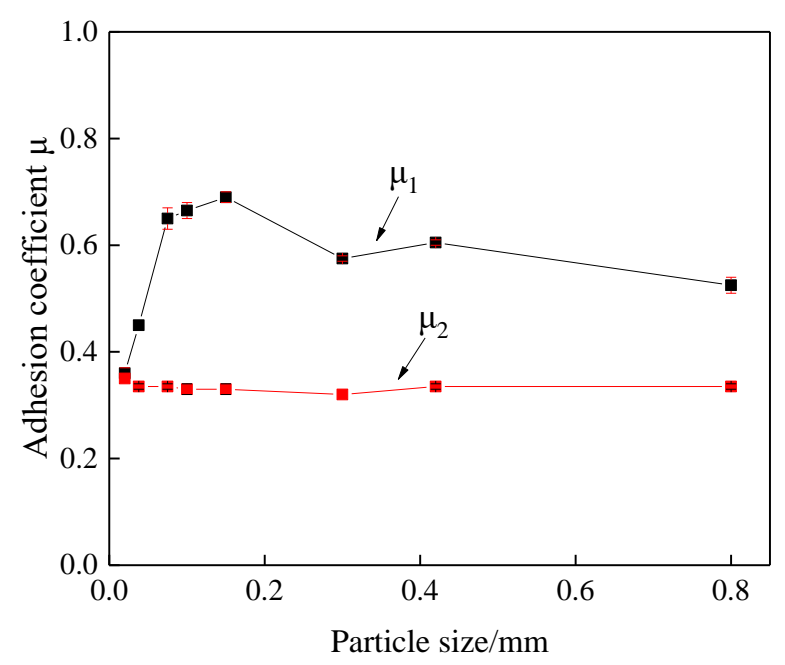

Fig.9. Effect of the particle size on $\mu_{1}$ and $\mu_{2}$.

\subsection{The duration of adhesion restoring effect after single application}

The variation processes of adhesion coefficient from the immediate increase to re-dropping to low level in different single application tests have also been recorded in Fig.10. Fig.11 gives an example to introduce the division of the different stages in the restored adhesion duration and to illustrate the good repeatability of tests. Three stages are distinguished in the adhesion restoring process: the first short duration $t_{1}$ with the immediate increase and rapid decrease of adhesion coefficient, the second stage $t_{2}$ with weak adhesion restoring effect but long duration and the third stage $t_{3}$ with the disappearance of the adhesion 
restoring effect.

As summarized in Fig.12, both the applied quantity and particle size have a large effect on the duration of different stages. The duration of the whole process $t_{0}$ increases with the applied quantity, but the increase slows down after the quantity exceeding $2 \mathrm{~g}$. This trend could also be observed in the variation of duration of the second stage $\left(t_{2}\right)$. However, the duration of the first $\left(t_{1}\right)$ and third stage $\left(t_{3}\right)$ seem to gets stable after the applied quantity exceeding $2 \mathrm{~g}$. As shown in Fig.12b, the maximum duration of $t, t_{1}, t_{2}$ and $t_{3}$ are all achieved at the size of $0.15 \mathrm{~mm}$. The duration increases with the grain size from 0.02 to $0.15 \mathrm{~mm}$ and then descends with the continuously increasing particle size and finally tends to be stable after the size exceeding $0.3 \mathrm{~mm}$.

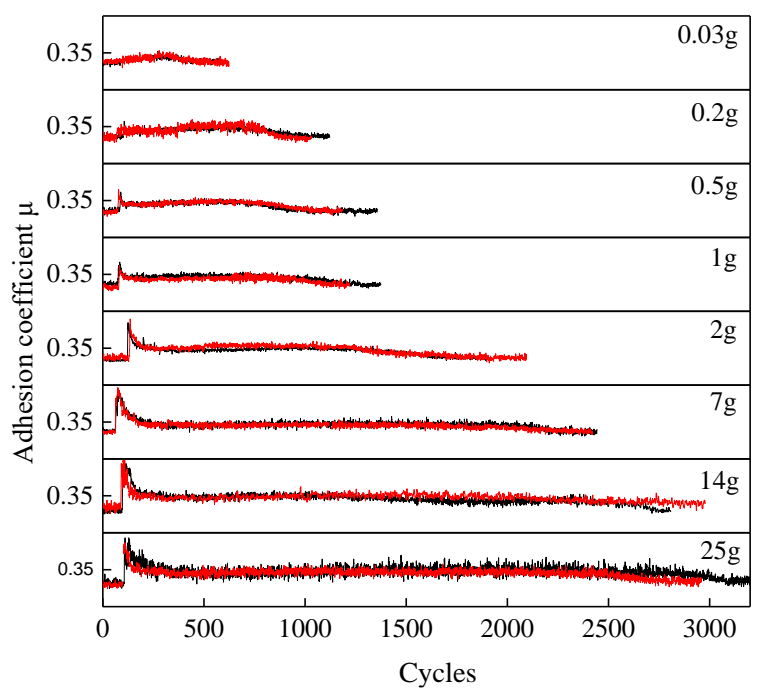

(a)

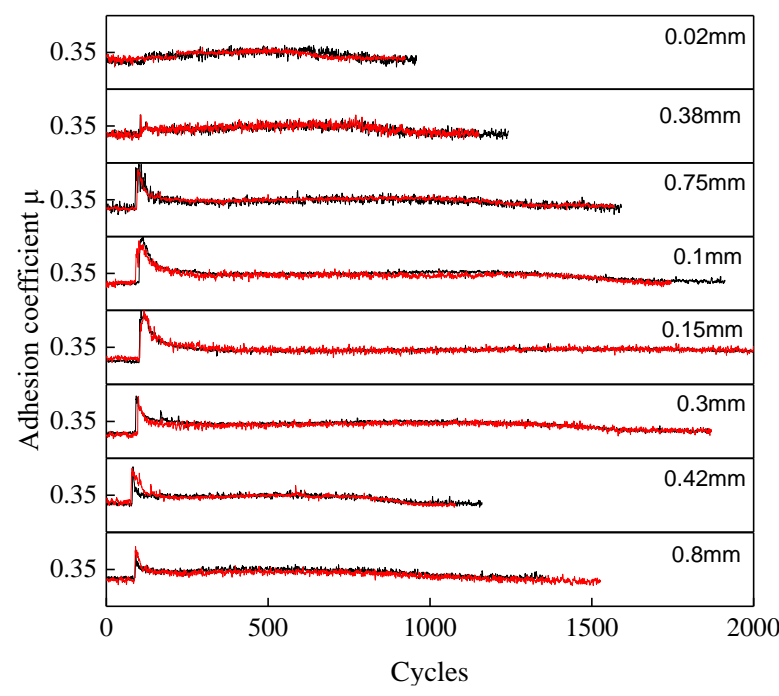

(b)

Fig.10. The whole variation process of adhesion coefficient after the application of alumina particles to the disappearance of the adhesion restoring effect, (a) with different quantities in the size of $0.3 \mathrm{~mm}$; (b) in different sizes with the quantity of $0.3 \mathrm{~g}$. 


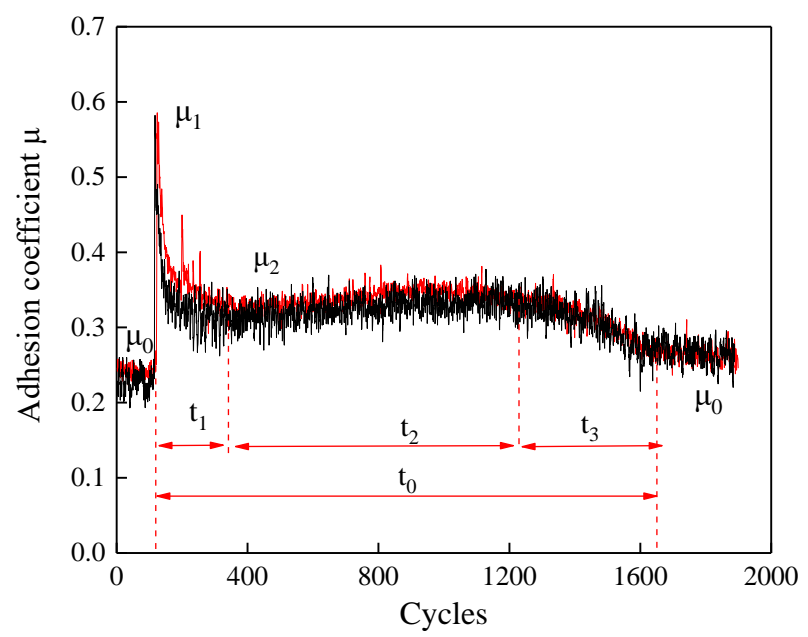

Fig.11. An example of the variation process to present the division of different durations (applied quantity:

$2 \mathrm{~g}$, particle size:0.3 mm)

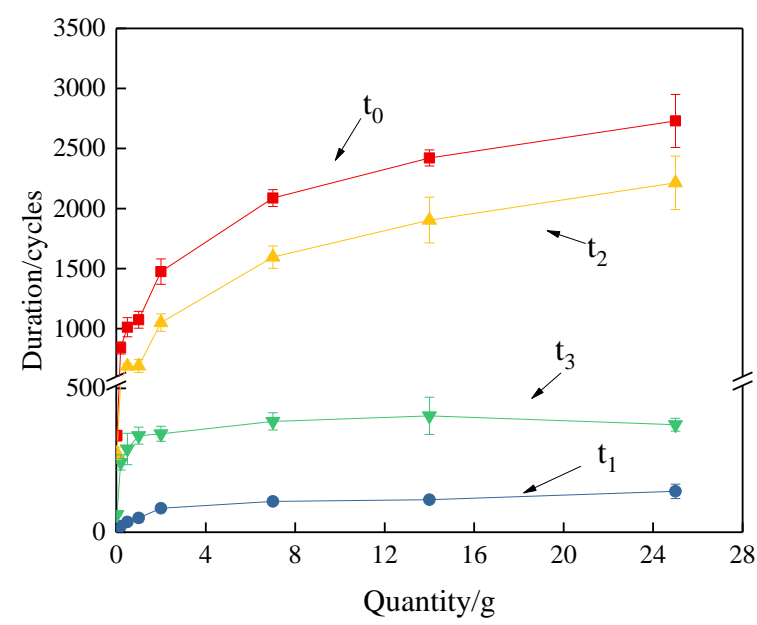

(a)

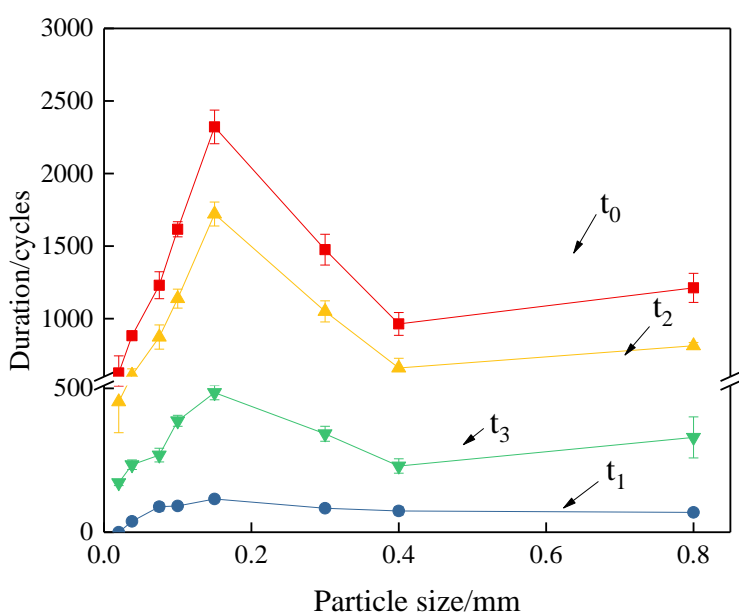

(b)

Fig.12. Effect of the applied quantity and particle size on the duration, (a) applied quantity; (b) particle size.

An interesting phenomenon is found in Fig.13a that the duration of restored adhesion could be shortened significantly under strong water flow condition. The restored adhesion coefficient $\mu_{1}$ is almost identical in different water flow cases, while the following adhesion coefficient $\mu_{2}$ is obviously larger in the smallest water flow case than that in other cases. In addition, when the alumina particles are applied under oil condition, as shown in Fig.13b, restored adhesion coefficient $\mu_{1}$ is below 0.4 , far lower than that under water condition. Moreover, there is only the first stage $t_{1}$ could be found after the application of alumina 
particles, meaning the adhesion restoration ability could not be held under oil condition. This may be caused by the larger film thickness at the contact interface under oil conditions.

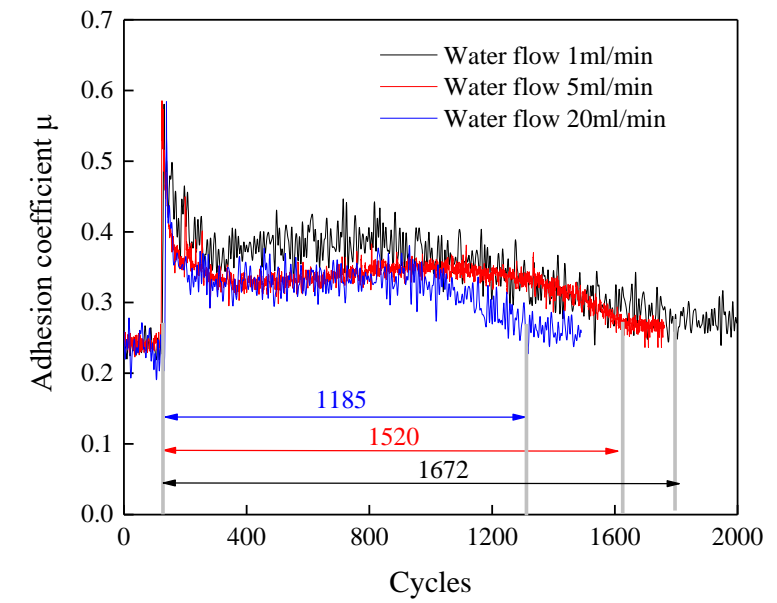

(a)

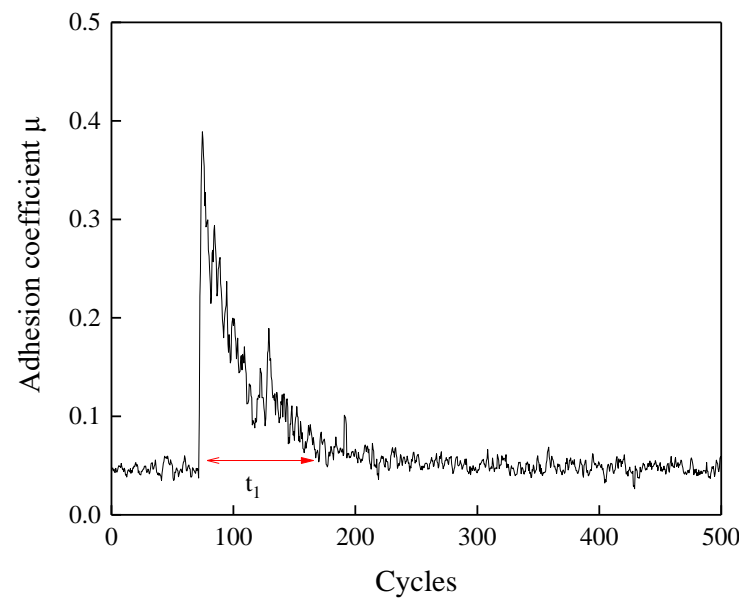

(b)

Fig.13. The variation process of adhesion coefficient after the application of alumina particles under different low adhesion conditions (applied quantity: $2 \mathrm{~g}$, particle size: $0.3 \mathrm{~mm}$ ), (a) wet conditions with different water flows; (b) oil condition.

\subsection{Damage evolution in the adhesion restoring process}

This part presents the surface damage of discs after a single application of alumina particles in the adhesion restoring process. The surface damage of wheel rollers at different stages is presented in Fig.14. Different from the slight damage produced after 5000 cycles running under wet condition at stage $\mathrm{A}$, the surface gets very rough and is covered with numerous embedded alumina particles at stage $\mathrm{B}$, at which the maximum adhesion coefficient has just been achieved after the application of alumina particles. Furthermore, it could be observed most of the alumina particles have been removed away from the rolling track from stage B to stage C (less than 400 cycles), although the surface is still visibly rough. In the end of process (stage D), when the adhesion coefficient has dropped to the wet level, the surface 
on the track recovers to be smooth again, while the rough surface with embedded alumina particles could still be found on the sides of the track.
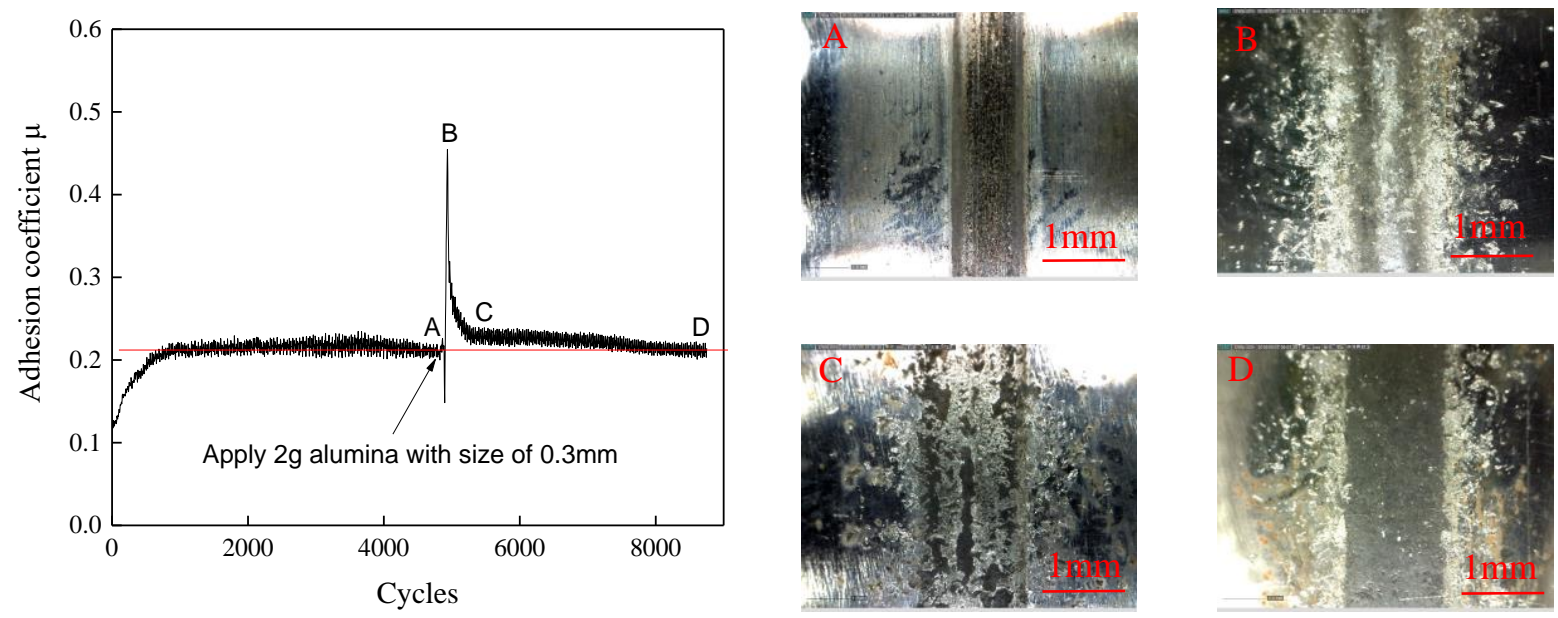

Fig.14. The surface topographies of wheel rollers at different stages.

As shown in Fig.15, the surface wear damage is obviously aggravated after the application of alumina particles from stage A to stage $\mathrm{B}$, due to the crushing of alumina particles at the contact interface. During the crushing process, initial particles with larger size will be crushed into lots of micro fragments when the normal load it withstands exceeds the particle strength. In addition, particles with sharp corners would be compressed into the wheel/rail materials for much higher hardness of alumina, leaving indentions and embedded fragments on the surface, as shown in Fig.15b. After a period of the mechanical remove of the crushed alumina particles in the rolling, only some micro particles, that have been embedded deeper, could be kept on the surface at stage C (Fig.15c). Thus, there are less alumina particles remaining on the track. In addition, it could also be found in the left figure of Fig.15c that there is a singular surface with darker color, which is peeling away with numerous micro cracks on it. When at stage D (Fig.15d), there are almost no embedded alumina particles and old surface found on the rolling track except in the border of the track, at which the 
mechanical shearing is weakest owing to the pressure distribution.
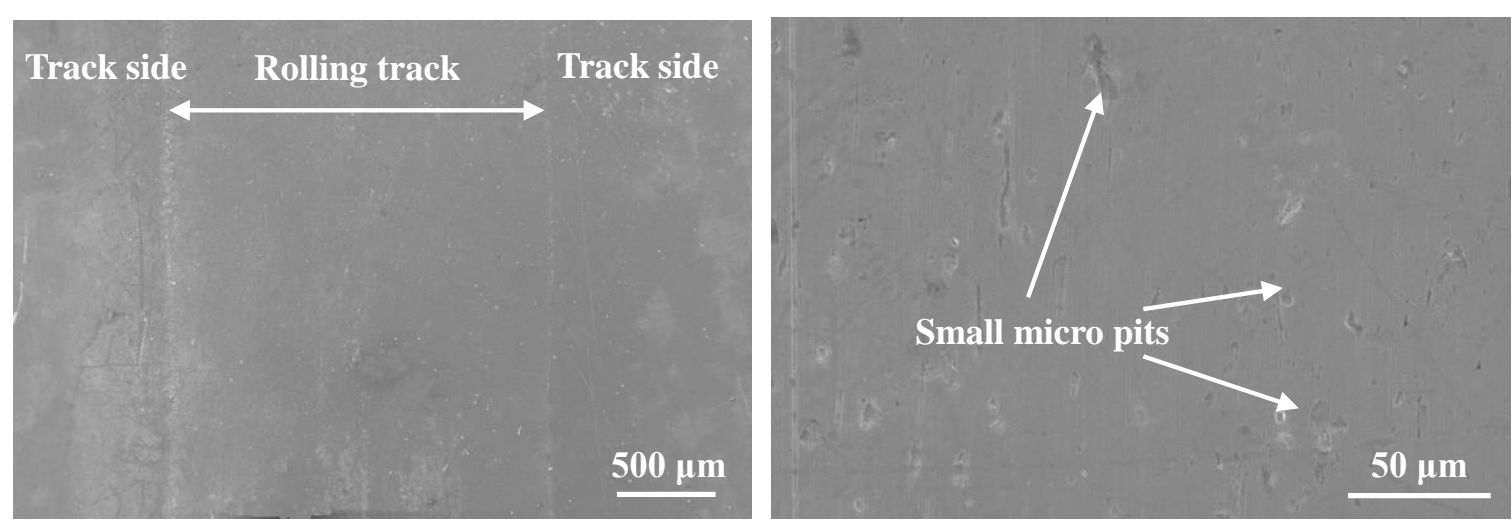

(a)
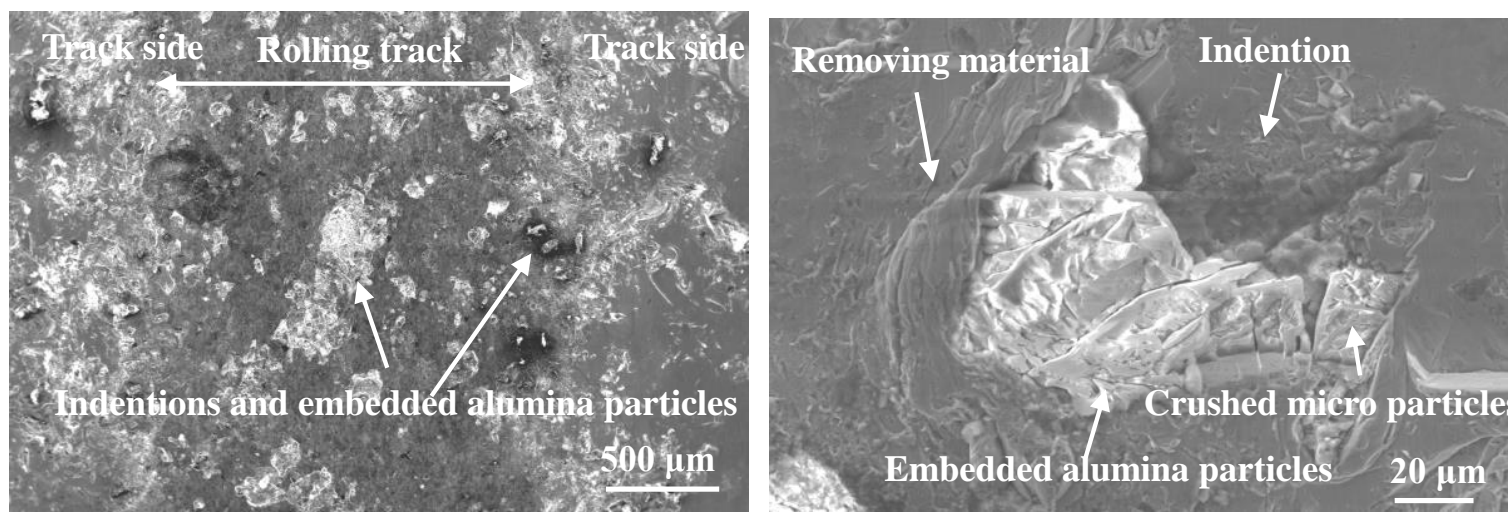

(b)
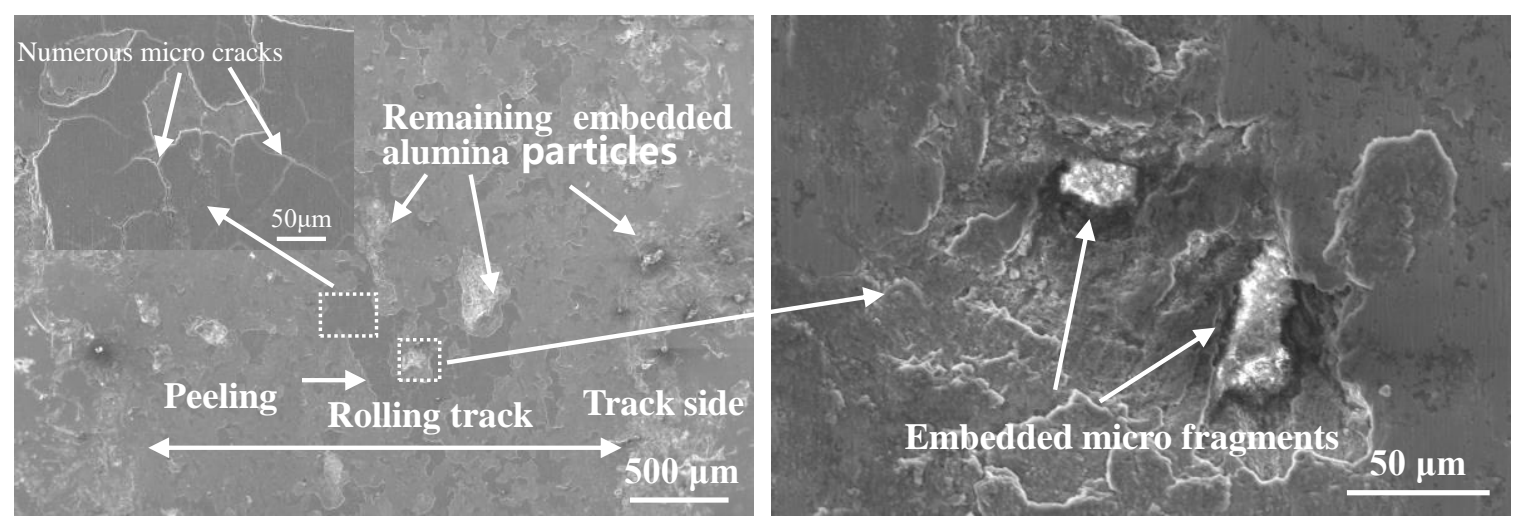

(c) 

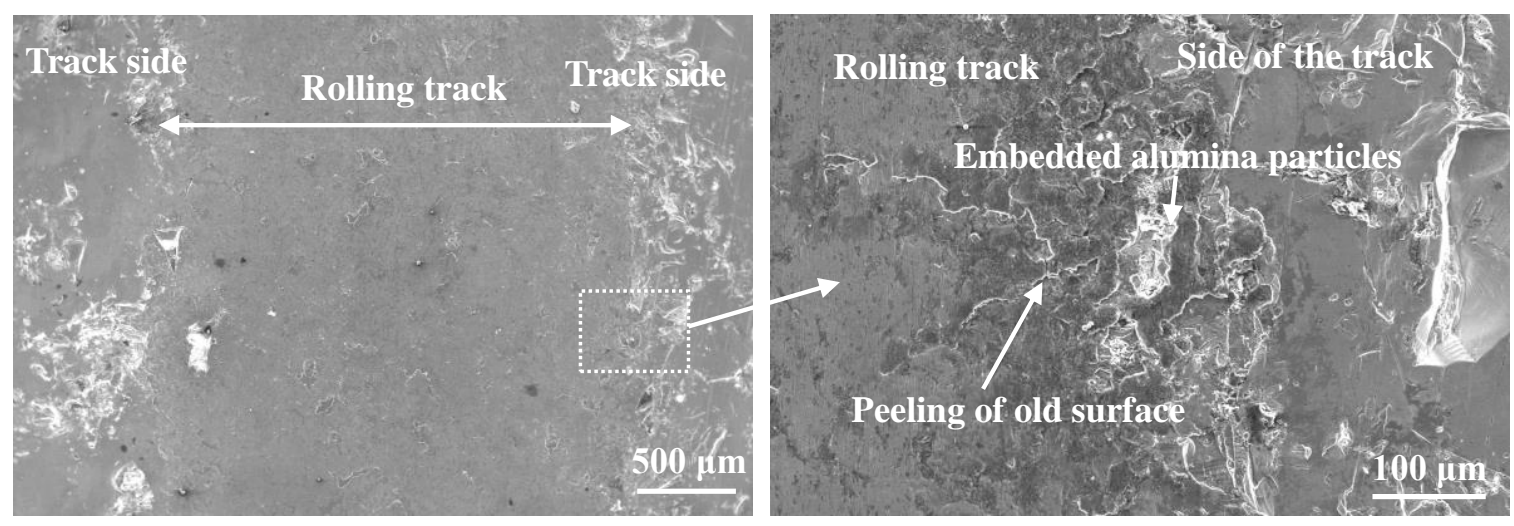

(d)

Fig.15. SEM micrographs of worn surfaces of wheel rollers at different stage (left: overall perspective;

right: details), (a) stage A; (b) stage B; (c) stage C; (d) stage D.

OM micrographs of longitudinal sections of wheel rollers at different stages are illustrated in Fig.16. There are no obvious cracks and plastic deformation on the subsurface at stage A. However, just a few cycles later after the application of alumina particles, obvious plastic deformation and embedded alumina particles could be observed at stage B. Except leaving indentation pits on the surface, another important adverse effect caused by the embedded particles is the severe plastic deformation of the material surrounding them, as shown in Fig.16b marked with red dot lines. The material over embedded particles will be highly strained in the rolling contact and get easy to be cut off, as shown in the picture attached in the lower left corner of Fig.16b. Therefore, lots of defects could be observed on the subsurface at stage $\mathrm{C}$ after most of the embedded alumina particles have been removed. Some micro embedded fragments with sizes less than $20 \mu \mathrm{m}$ could still be found on the surface or at the bottom of the indentations. Most importantly, the material at the top of the crack-like cavies has been highly strained to be cut off and this could be correlated to the peeling of the surface with numerous micro cracks presented in Fig.15c. At the end of the 
process (stage D), almost all the embedded alumina fragments and the highly strained layer have been removed and there are only some shallow pits and micro cracks could be found on the subsurface, as shown in Fig.16d. Therefore, it could be inferred that serious damage caused by the application of alumina particles is mainly produced in the crushing process and the damage will get alleviated in the following long-time running.

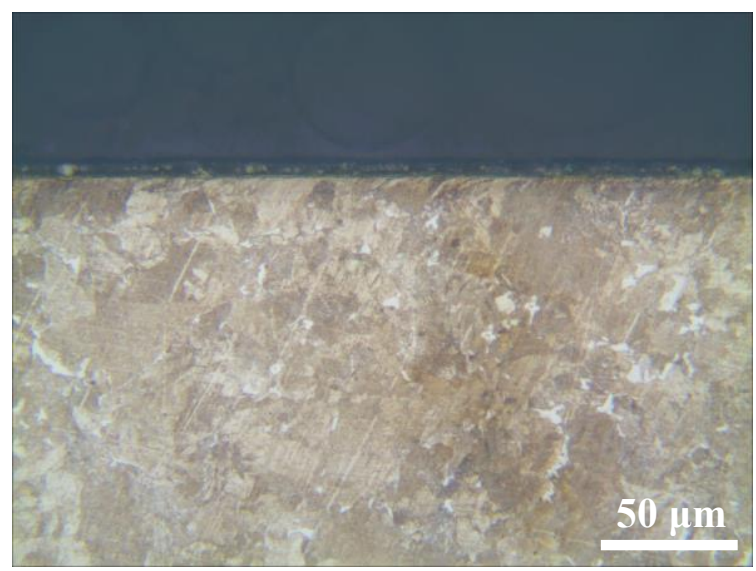

(a)

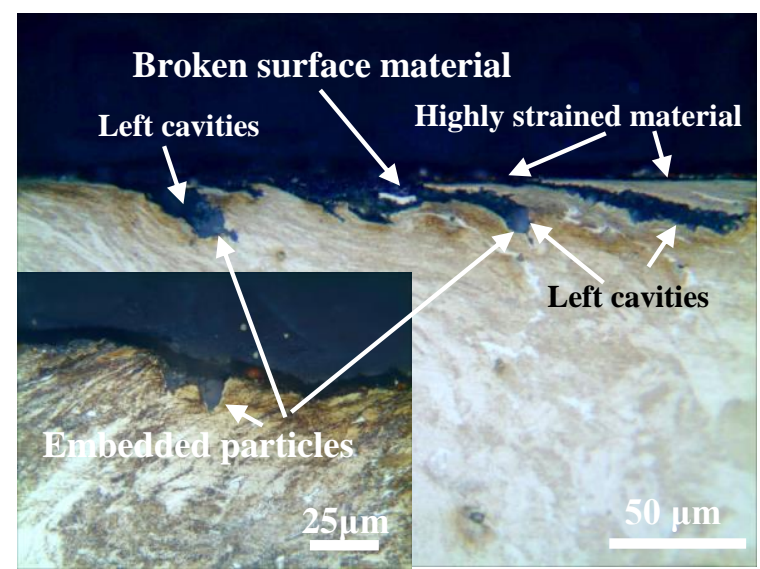

(c)

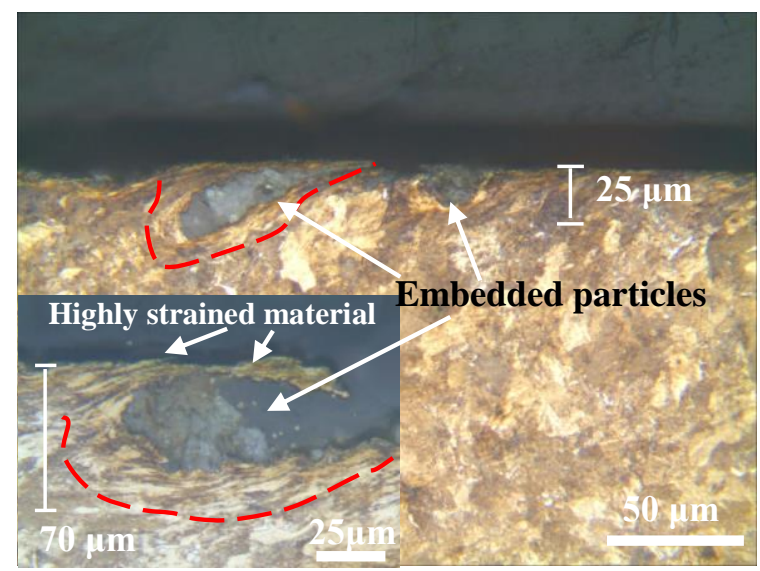

(b)

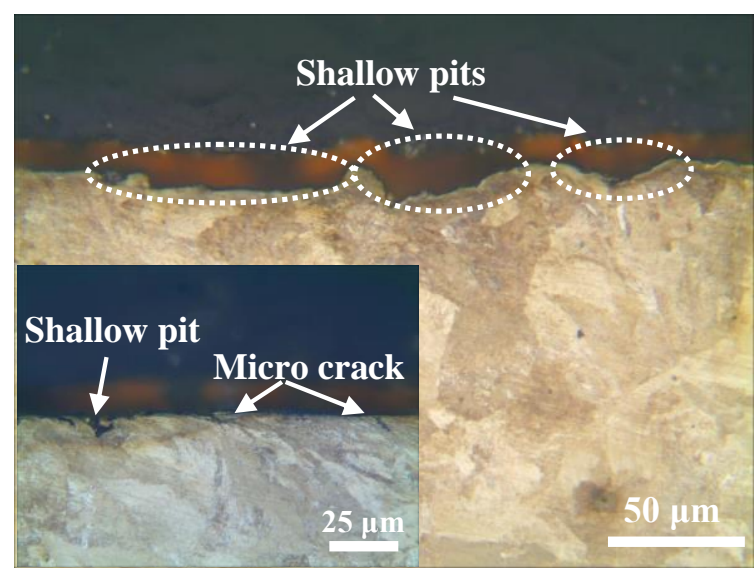

(d)

Fig.16. OM micrographs of longitudinal section of wheel rollers at different stage, (a) stage A; (b) stage B;

(c) stage C; (d) stage D.

\section{Discussion}




\subsection{Comparison of continuous and single application of particles in the laboratory}

This study has firstly explored the adhesion restoration of alumina particles using both continuous and single application testing strategies on the JD-1 wheel/rail test rig. Table 4 lists the corresponded sand deposition rates in these two strategies, which are calculated based on the different customs used in previous continuous [21, 26] and single application studies $[27,28]$. It is obvious the results coming from comparing these two different test strategies are distinct. In the continuous application, the restored adhesion coefficient increases with the deposition rate until reaching the threshold of $0.076 \mathrm{~g} / \mathrm{m}(30 \mathrm{~g} / \mathrm{min})$, above which the adhesion restoring ability of solid particles is weakened significantly. In the single application, there is also a threshold of the deposition rate. However, this threshold is much larger $(0.67$ $\mathrm{g} / \mathrm{m}$ ) and the adhesion restoring ability gets stable when the deposition rate further increases from this threshold to the limited $7.5 \mathrm{~g} / \mathrm{m}$. This trend seems to be more approximate to the practice and Lewis's linear full-scale test results [23].

In the continuous application, there is always a part of the applied material remaining on the discs surface and coming into the contact repeatedly. So, the actual quantity of the active particles at the interface increase gradually and the true deposition rate becomes much larger than expected. At low flow rates, the elevating particles density helps to increase the adhesion coefficient and will lead its adhesion restoration overestimated. While, at high flow rates, this elevation will easily make the contact overdosed. Then a compacted crushed particles coating will be formed by the excessive solid particles in the contact, diminishing the adhesion restoring ability $[27,28]$. In this case, the achieved effect could not be correlated to the actual tested deposition rate, because the wheels just pass through the laid particles once in the field. 
In the single application tests, as the application of alumina particles takes a short time (less than 2 cycles), the followed improvement of adhesion coefficient could be directly attributed to the applied quantity. And considering the remove of particles in this transient process will not loss too much, it could be regarded such the applied particles are uniformly deposited on the disc circumference. Therefore, the improved adhesion coefficient could be correlated to a relatively precise deposition rate used in the field and the appropriate deposition rate achieved by this test strategy could be more convincing to guide the field application.

Table 4. Comparison of the adhesion restoration using continuous and single application of alumina

particles (particle size: $0.3 \mathrm{~mm}$ ).

\begin{tabular}{cccccc}
\hline \multicolumn{3}{c}{ Continuous application } & & \multicolumn{3}{c}{ Single application } \\
\hline $\begin{array}{c}\text { Flow } \\
\text { rate/g/min }\end{array}$ & $\begin{array}{c}\text { Expected sand } \\
\text { deposition } \\
\text { rate/g/m }\end{array}$ & $\begin{array}{c}\text { Average } \\
\text { adhesion } \\
\text { coefficient }\end{array}$ & $\begin{array}{c}\text { Applied } \\
\text { quantity/g }\end{array}$ & $\begin{array}{c}\text { Expected sand } \\
\text { deposition } \\
\text { rate/g/m }\end{array}$ & $\begin{array}{c}\text { Adhesion } \\
\text { coefficient }\end{array}$ \\
\hline 1.5 & 0.004 & 0.41 & 0.03 & 0.009 & 0.31 \\
12 & 0.030 & 0.54 & 0.2 & 0.061 & 0.40 \\
30 & 0.076 & 0.56 & 0.5 & 0.152 & 0.42 \\
60 & 0.152 & 0.43 & 1 & 0.303 & 0.45 \\
125 & 0.316 & 0.44 & 2 & 0.607 & 0.58 \\
200 & 0.506 & 0.4 & 7 & 2.123 & 0.65 \\
500 & 1.264 & 0.3 & 14 & 4.246 & 0.65 \\
- & & - & 25 & 7.582 & 0.64 \\
\hline
\end{tabular}

Furthermore, sanding is carried out sporadically in the field and the wheels would pass through the deposited sand just for a short time in its serving life. Previous investigations on the wheel/rail wear and RCF damage during application of sand or alumina particles were mainly conducted in continuous application tests $[15,17,21,24-26]$. The results in Section 
3.4 have indicated that serious damage is mainly connected with a crushing process of the applied particles. It is expected that the serious damage observed in the continuous application test, especially at a higher flow rate or large particle size, may be overestimated compared to a real situation due to the longer lasting crushing of the applied material. In this study, the crushing process is transient compared to the long running of the rollers before and after the single-application of alumina particles. The applied quantity was set as $2 \mathrm{~g}$, which corresponds to the deposition rate of app. $25.5 \mathrm{~g} / \mathrm{m}$ for the MJP rollers and represents the worst situation. The initial reduction of adhesion coefficient after the application shown in Fig.14 is related to the formation of a solid lubrication layer in the interface due to the excessive application. It can be found that the serious damage after the transient crushing process lasting a few cycles is close to that achieved in a more than 20000 cycles of continuous application of alumina particles [26]. Without the supplement of new particles in the following cycles, the severe damage caused during crushing process is gradually rounded off in the following running. Therefore, unlike the conclusions drawn based on the continuous application, the damage caused by sporadically applied alumina does not seem so serious to threat the serving life of the wheel and the rail.

Based on the above analysis, it could be expected that the single application performs better in simulating the practical deposition rate and wheel/rail damage. Perhaps, the continuous application test strategy will still be used in the future studies for some other benefits. However, there should be some improvements taken into consideration for the estimation of the accurate deposition rate at the rollers contact interface.

\subsection{Effect of applied quantity and particle size on the adhesion restoration}


After the application of alumina particles, they are crushed into micro fragments when passing through the contact. During this process some fragments fly away from the interface and some of them remain embedded into the wheel/rail material (stage B in Fig.15b) or just freely on the surface. These fragments play an active role on the adhesion enhancement. Nevertheless, they are gradually removed from the contact if no further particles are applied.

To describe the particle removal process, the mass concentration of alumina in water dripping out from the rollers was evaluated in each drop during the last wear test. The results are compared with the evolution of adhesion coefficient in Fig. 4. The maximum adhesion coefficient corresponds to the highest concentration of alumina in white-color slurry mixed in the contact. After that, in line with the rapid washing out of the free particles, both the concentration and adhesion coefficient decrease rapidly. At stage $\mathrm{C}$, although the concentration has dropped to a quite low level, there are still some embedded particles that provide enhanced adhesion. Both the quantity and size of the embedded particles are not large enough to improve the adhesion coefficient strongly but could maintain it at a weak level $(\mu 2)$ that is close to the application of $2 \mathrm{~g}$ of alumina particles having $0.02 \mathrm{~mm}$ (Fig.8a). At the last stage $\mathrm{D}$, adhesion coefficient drops back to the low level once alumina particles are almost completely removed.

Increase in the quantity of applied alumina particles increases directly the number of the free particles available in the contact that is crucial for the improved adhesion coefficient $\mu 1$ and corresponding period $\mathrm{t} 1$. There is a rapid increase of $\mu 1$ and $\mathrm{t} 1$ when the applied quantity changes from 0.03 to $7 \mathrm{~g}$ (Fig.7 and Fig.12a). However, there is some limiting quantity of the active particles, over which other particles cannot effectively work in the contact [26]. So, 
both $\mu 1$ and $\mathrm{t} 1$ could not be further improved when the applied quantity is increased from 7 to $25 \mathrm{~g}$. In addition, with the increase of applied quantity, there will be more fragments embedded on the surface, as has been proved by Cao using different feed rate of continuous application of alumina particles [25]. Therefore, the duration t2 of removing the embedded particles is always increased with the increase of applied quantity. However, as the size of embedded fragments is less than $50 \mu \mathrm{m}$, the adhesion coefficient could not be kept at a high level due to the small volume of them (as proved in Fig.8a and b).

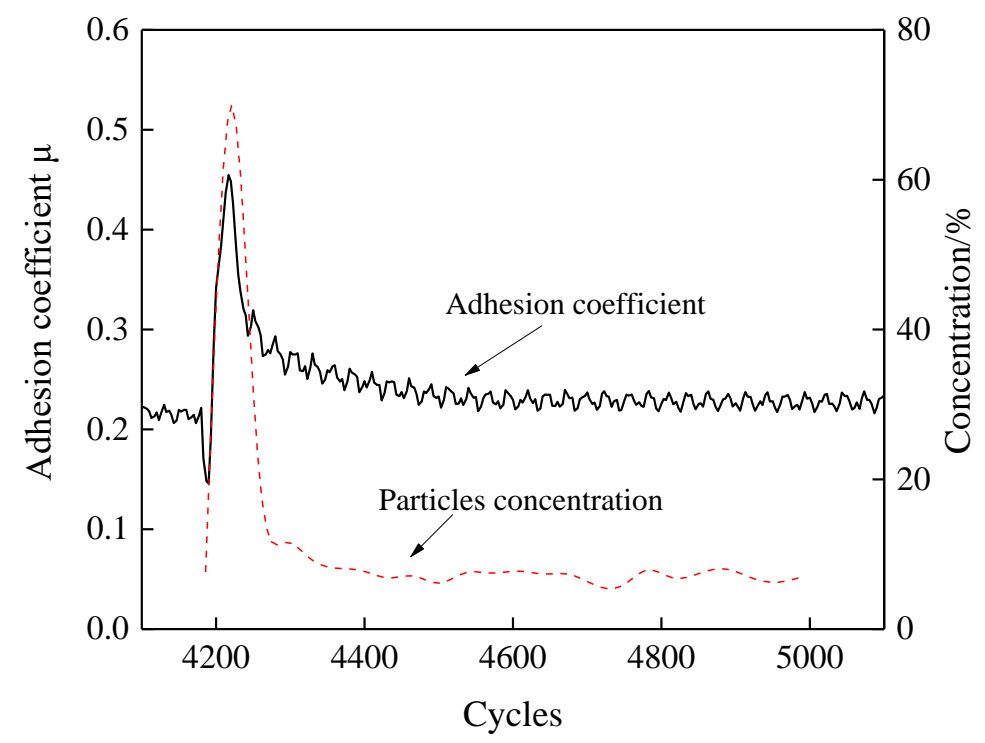

Fig.17. Variation of the adhesion coefficient and alumina particles concentration recorded in the last wear test.

When the alumina particles of different particle size are applied, one important factor is the loss of fragments in the particle breaking process. Breakage of larger particles requires lager breakage energy and causes that more fragments are flying away from wheel/rail surface [33]. For this reason, the best adhesion enhancement is achieved by the particles at the size of $0.075,0.1$ and $0.15 \mathrm{~mm}$, while the improved adhesion coefficient decreases obviously for the particles of the size of $0.8 \mathrm{~mm}$. This finding agrees with the 
observation in Cao's study [25]. It was also found that the longest duration of each stage in adhesion restoration have the particles at the size of $0.15 \mathrm{~mm}$ (Fig.13). This phenomenon could not be interpreted clearly as the breakage process is very complex. On one hand, compared to the smaller particles, there are more active particles left or embedded on the surface after the crushing at size of $0.15 \mathrm{~mm}$. On the other hand, the particles loss during the crushing is smaller than for larger particles.

\section{Conclusions}

1. This study indicates the single application of solid particles in the twin disc simulation is more suitable to evaluate the adhesion restoring ability and wheel/rail damage than the continuous application test strategy.

2. Increasing the particles quantity in the single application could improve the restored adhesion and prolong the adhesion restoration duration until reaching the threshold quantity of $2 \mathrm{~g}$ (deposition rate of $0.67 \mathrm{~g} / \mathrm{m}$ ). Above this threshold, the restored adhesion coefficient turns to be stable and the increment of the duration slows down.

3. The best adhesion restoration was achieved by alumina particles at the size in the range of 0.075 to $0.15 \mathrm{~mm}$, and the longest duration was achieved at the size of $0.15 \mathrm{~mm}$.

4. Serious damage is mainly produced in the initial crushing process of applied alumina particles and this damage will gradually fade away in the following long running. Thus, it could be believed that the damage caused in the adhesion restoration is not a threatening problem for the long serving lives of wheel and rail. 


\section{Acknowledgments}

The work is supported by Sichuan Science and Technology Program (No. 2018GZ0368), National Natural Science Foundation of China (Nos. 51775455 and 51575460) and Cultivation Program for the Excellent Doctoral Dissertation of Southwest Jiaotong University.

The authors are sincerely grateful to European Commission for the financial sponsorship of the H2020-MSCA-RISE Project No. 691135 "RISEN: Rail Infrastructure Systems Engineering Network", which enables a global research network that tackles the grand challenge in railway infrastructure resilience and advanced sensing under extreme environments.

\section{References}

[1]Ohyama. Fundamental adhesion phenomena between wheel and rail at high speeds, some experiments with a high speed rolling test machine under water, QR of RTRI. 26 (1985) 135-140.

[2]Chen, T. Ban, M. Ishida, T. Nakahara, Experimental investigation of influential factors on adhesion between wheel and rail under wet conditions, Wear 265 (2008) 1504-1511.

[3]W.J. Wang, H. Wang, H.Y. Wang, J. Guo, Q.Y. Liu, M.H. Zhu, X.S. Jin, Sub-scale simulation and measurement of railroad wheel/rail adhesion under dry and wet conditions, Wear 302 (2013) 1461-1467.

[4]E.A. Gallardo-Hernandez, R. Lewis, Twin disc assessment of wheel/rail adhesion, Wear 265 (2008) 1309-1316.

[5]D.A. Green, R. Lewis, The effects of soot-contaminated engine oil on wear and friction: A 
review, Proc. ImechE, Part D: J. Automobile Engineering. 222 (2008) 1669-1689.

[6]P.M. Cann. The "leaves on the line" problem — a study of leaf residue film formation and lubricity under laboratory test conditions, Tribol. Lett. 24 (2006) 151-158.

[7]Y. Zhu, U. Olofsson, R. Nilsson, A field test study of leaf contamination on railhead surfaces, Proc. ImechE, Part F: J. Rail Rapid Transit. 228 (2012) 71-84.

[8]K. Ishizaka, S.R. Lewis, R. Lewis, The low adhesion problem due to leaf contamination in the wheel/rail contact: Bonding and low adhesion mechanisms, Wear 378-379 (2017) 183-197.

[9]S. Descartes, C. Desrayaud, E. Niccolini, Y. Berthier, Presence and role of the third body in a wheel-rail contact, Wear 258 (2005) 1081-1090.

[10]E. Niccolini, Y. Berthier, Wheel-rail adhesion: laboratory study of "natural" third body role on locomotives wheels and rails, Wear 258 (2005) 1172-1178.

[11]U. Olofsson. A multi-layer model of low adhesion between railway wheel and rail, Proc. ImechE, Part F: J. Rail Rapid Transit, 221 (2007) 385-389.

[12]Y. Zhu, H. Yang, W. Wang, Twin-disc tests of iron oxides in dry and wet wheel-rail contacts, Proc. ImechE, Part F: J. Rail Rapid Transit 230 (2015) 1066-1076.

[13]R. Galas, M. Omasta, I. Krupka, M. Hartl, Laboratory investigation of ability of oil-based friction modifiers to control adhesion at wheel-rail interface, Wear 368-369 (2016) 230-238.

[14]H.I. Andrews, Railway traction - the principles of mechanical and electrical Railway Traction, Elsevier, 1986, pp. 33-62.

[15]S. Kumar, P.K. Krishnamoorthy, D.L.P. Rao, Wheel-rail wear and adhesion with and without sand for north American locomotive, Journal of Engineering for Industry, 
Transactions of the ASME, 108 (1986) 141-147.

[16]R. Galas, D. Kvarda, M. Omasta, I. Krupka, M. Hartl. The role of constituents contained in water-based friction modifiers for top-of-rail application, Tribol. Int. 117 (2018) 87-97.

[17]W.J. Wang, T.F. Liu, H.Y. Wang, Q.Y. Liu, M.H. Zhu, J.X Jin, Influence of friction modifiers on improving adhesion and surface damage of wheel/rail under low adhesion conditions, Tribol. Int. 75 (2014) 16-23.

[18]K. Ohno, T. Ban, T. Obara, K. Kawaguchi, Development a new method for adhesion improvement replacing traditional sanding, Proceedings of the international heavy haul association, 1994, pp. 57.

[19]RSSB: GM/RT2461, Sanding Equipment Fitted to Multiple Units and On-Track Machines, Issue One: August 2001, Rail Safety and Standards Board, Block2, Angel Square, 1 Torrens Street, London EC1V 1NY.

[20]TB/T 3254-2011, Sanding device of locomotive and motor car, Standards of the Railway Industry of the People's Republic of China.

[21]O. Arias-Cuevas, Z. Li, R. Lewis, A laboratory investigation on the influence of the particle size and slip during sanding on the adhesion and wear in the wheel-rail contact, Wear $271(2001) 14-24$.

[22] O. Arias-Cuevas, Z.L. Li, Field investigations into the adhesion recovery in leaf-contaminated wheel-rail contacts with locomotive sanders. Proc. ImechE, Part F: J. Rail Rapid Transit, 225 (2011) 443-456.

[23]S. Lewis, S. Riley, D.I. Fletcher, R. Lewis, Optimisation of a railway sanding system, Part2: Adhesion Tests. in: Proceedings of the $10^{\text {th }}$ International Conference on Contact 
Mechanics and Wear of Rail/Wheel System (CM2015), Colorado, USA, 2015.

[24] W.L. Huang, X. Cao, Z.F. Wen, W.J. Wang, Q.Y. Liu, M.H. Zhu, X.S. Jin. A subscale experimental investigation on the influence of sanding on adhesion and rolling contact fatigue of wheel/rail under water condition. Journal of Tribology, Transactions of the ASME, 2017, 139(1):11401-11408.

[25] X. Cao, W.L. Huang, C.G. He, J.F. Peng, J. Guo, W.J. Wang, Q.Y. Liu, M.H. Zhu, The effect of alumina particle on improving adhesion and wear damage of wheel/rail under wet conditions, Wear 348-349 (2016) 98-115.

[26] R. Lewis, R. S. Dwyer-Joyce, Wear at the wheel/rail interface when sanding is used to increase adhesion. Proc. ImechE, Part F: J. Rail Rapid Transit, 220 (2006) 29-41.

[27] M. Omasta, M. Machatka, D. Smejkal, M. Hartl, I. Křupka, Influence of sanding parameters on adhesion recovery in contaminated wheel-rail contact, Wear 322-323 (2015) 218-225.

[28] O. Arias-Cuevas, Z.L. Li, R. Lewis, E.A. Gallardo-Hernández, Laboratory investigation of some sanding parameters to improve the adhesion in leaf-contaminated wheel-rail contacts. Proc. ImechE, Part F: J. Rail Rapid Transit, 308 (2010) 139-157.

[29] O. Arias-Cuevas, Z. Li, R. Lewis. Investigating the lubricity and electrical insulation caused by sanding in dry wheel-rail contacts. Tribol. Lett. 37 (2010) 623-635.

[30] W.J. Wang, H.Y. Wang, J. Guo, Q.Y. Liu, M.H. Zhu, X.S. Jin. Experimental investigation of adhesion coefficient of wheel/rail under the track ramp conditions. Proc. ImechE, Part J: J. Engineering Tribology, 228 (2014) 808-815.

[31] W.T. Zhu, L.C. Guo, L.B. Shi, Z.B. Cai, Q.L. Li, Q.Y. Liu, W.J. Wang, Wear and damage 
transitions of two kinds of wheel materials in the rolling-sliding contact, Wear 298-299 (2018) 79-89.

[32] M. Faccoli, C. Petrogalli, M. Lancini, A. Ghidini, A. Mazzu, Effect of desert sand on wear and rolling contact fatigue behaviour of various railway wheel steels, Wear 396-397 (2017) 146-161.

[33] Y. Nakata, M. Hyodo, A.F.L. Hyde, Y. Kato, H. Murata, Microscopic particle crushing of sand subjected to high pressure one-dimensional compression, Soils Found, 41 (2001) 69-82. 